\title{
THE METABOLIC EFFECTS OF STEROID HORMONES IN OSTEOPOROSIS
}

\author{
By EDWARD C. REIFENSTEIN, JR., AND FULLER ALBRIGHT 1, 2, 8 \\ (From the Medical Service of the Massachusetts General Hospital and the Department of \\ Medicine of the Harvard Medical School, Boston)
}

(Received for publication May 7, 1946)

In a previous communication from this clinic (1), three metabolic studies on the effect of estradiol benzoate on the calcium and phosphorus metabolisms of patients with post-menopausal osteoporosis were published in abstract form. The first objective of the present paper is to report these studies in detail, supplemented by 2 additional studies: one in which testosterone propionate by itself, and in combination with estradiol benzoate, was used; and another in which diethylstilbestrol by itself, and in combination with progesterone, was employed. The subject of the

1 The expense of these studies was defrayed by grants from the Josiah Macy, Jr. Foundation, from the Rockefeller Foundation, and from the National Research Council (Committee for Research in the Problems of Sex). A bed supported by the Mallinckrodt Chemical Company on the Metabolic Ward was used for part of these studics.

2 Presented in part at the twenty-sixth annual meeting of the Association for the Study of Internal Secretions, Atlantic City, New Jersey, June 8, 1942, in connection with a symposium on "Relation of Endocrines to Skeletal Development"; an outline of this presentation may be found in: Reifenstein, E. C., Jr.; Albright, F.; Parson, W.; and Bloomberg, E.: The effect of estradiol benzoate and of testosterone propionate and of combinations of both on post-menopausal osteoporosis and senile osteoporosis, Endocrinology, 30: S1024 (1942). Also presented in part at the first annual meeting of the American Federation for Clinical Research, Minneapolis, Minn., April 20, 1942. Preliminary reports of part of these data may be found in: Albright, F.; Reifenstein, E. C., Jr.; and Forbes, A. P.: Conferences on the Metabolic Aspects of Convalescence (Including Bone and Wound Healing), Transactions of the First Meeting, Sept. 11-12, 1942, pages 5-7, 37-38; Transactions of the Second Meeting, December 11-12, 1942, pages 69, 96-98; Transactions of the Third Meeting, March 12-13, 1943, pages 63-65; and Transactions of the Fourth Meeting, June 11-12, 1943, pages 77-85. Transactions distributed by the Josiah Macy, Jr. Foundation, New York, N. Y.

3 The work described in this paper was done in part under a contract, recommended by the Committee on Medical Research, between the Office of Scientific Research and Development and the Massachusetts General Hospital. last investigation had, in addition to post-menopausal osteoporosis, Paget's disease.

The second objective is to publish metabolic studies on the effect of testosterone propionate alone and in combination with estradiol benzoate in a male patient with senile osteoporosis.

The third objective is to present studies on 3 patients with the acute osteoporotic process which follows orthopedic operations, and the effect of estradiol benzoate on this process in 2 of these subjects.

In another previous communication from this clinic (2), metabolic studies of the effect of estradiol benzoate, testosterone propionate, and progesterone on 3 patients with Cushing's syndrome were reported. The fourth objective is to present these data more completely in graphic form, and especially to rectify an unwarranted conclusion as to the effect of estrogen on the calcium balance.

\section{DEFINITION OF OSTEOPOROSIS}

Osteoporosis is not synonymous with demineralization of bone; it is that category of too-littlebone where the primary disturbance is lack of bone matrix formation. It is not to be confused with osteomalacia, where the primary disturbance is failure of mineralization of bone, or with osteitis fibrosa generalisata, where the primary disturbance is increased bone destruction. For further discussion, see $(1,3,4)$.

\section{CONDITIONS ASSOCIATED WITH OSTEOPOROSIS}

In clinical medicine one encounters the following conditions associated with osteoporosis: (1) disuse atrophy, where the normal stimulus to osteoblastic activity is absent $(4,5)$; (2) old age, where the bone tissue like other tissue (cf. hair, skin, muscles) atrophies; (3) malnutrition, where the protein requirements are not fulfilled, and the bone matrix, like other tissues, is depleted; (4) 


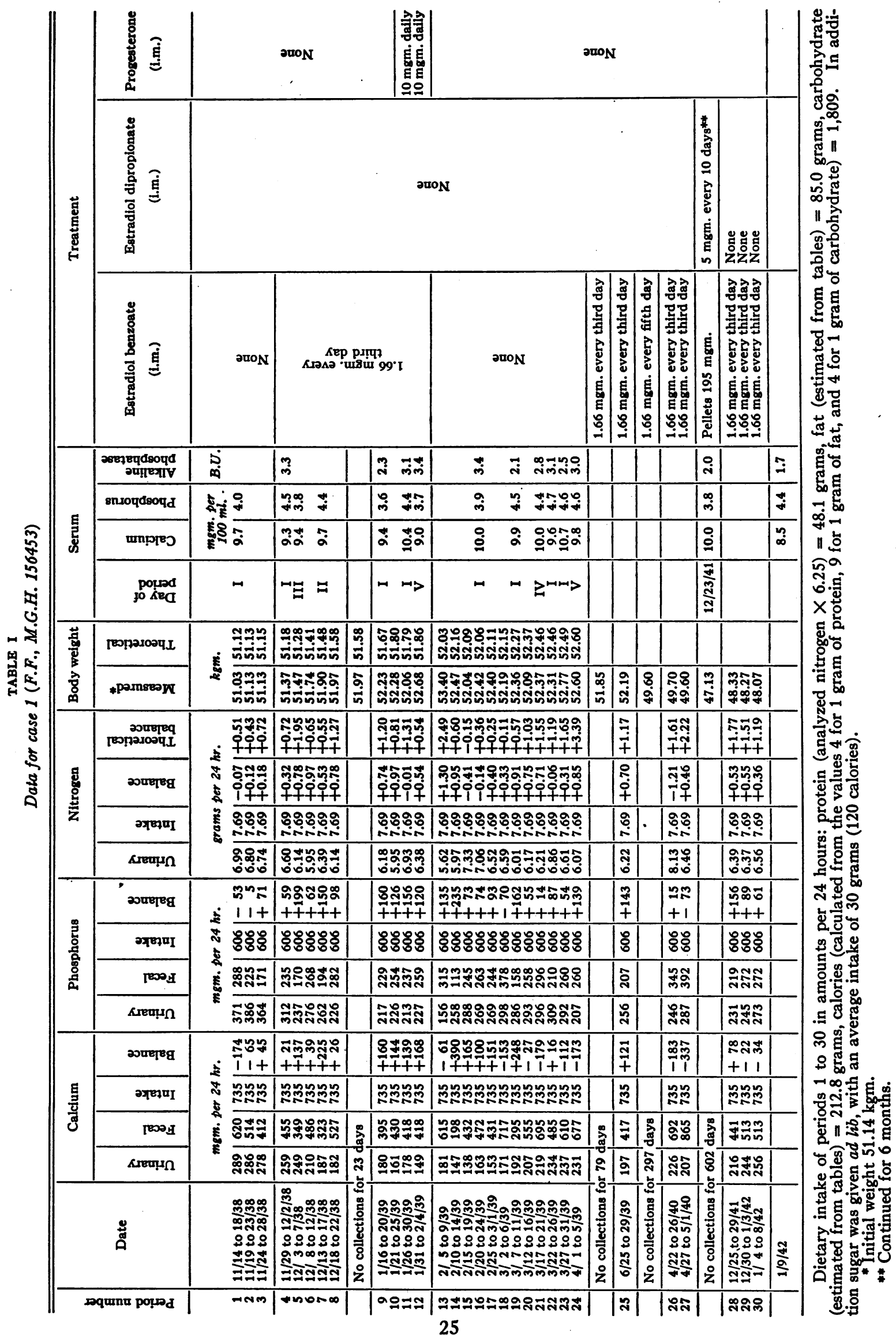




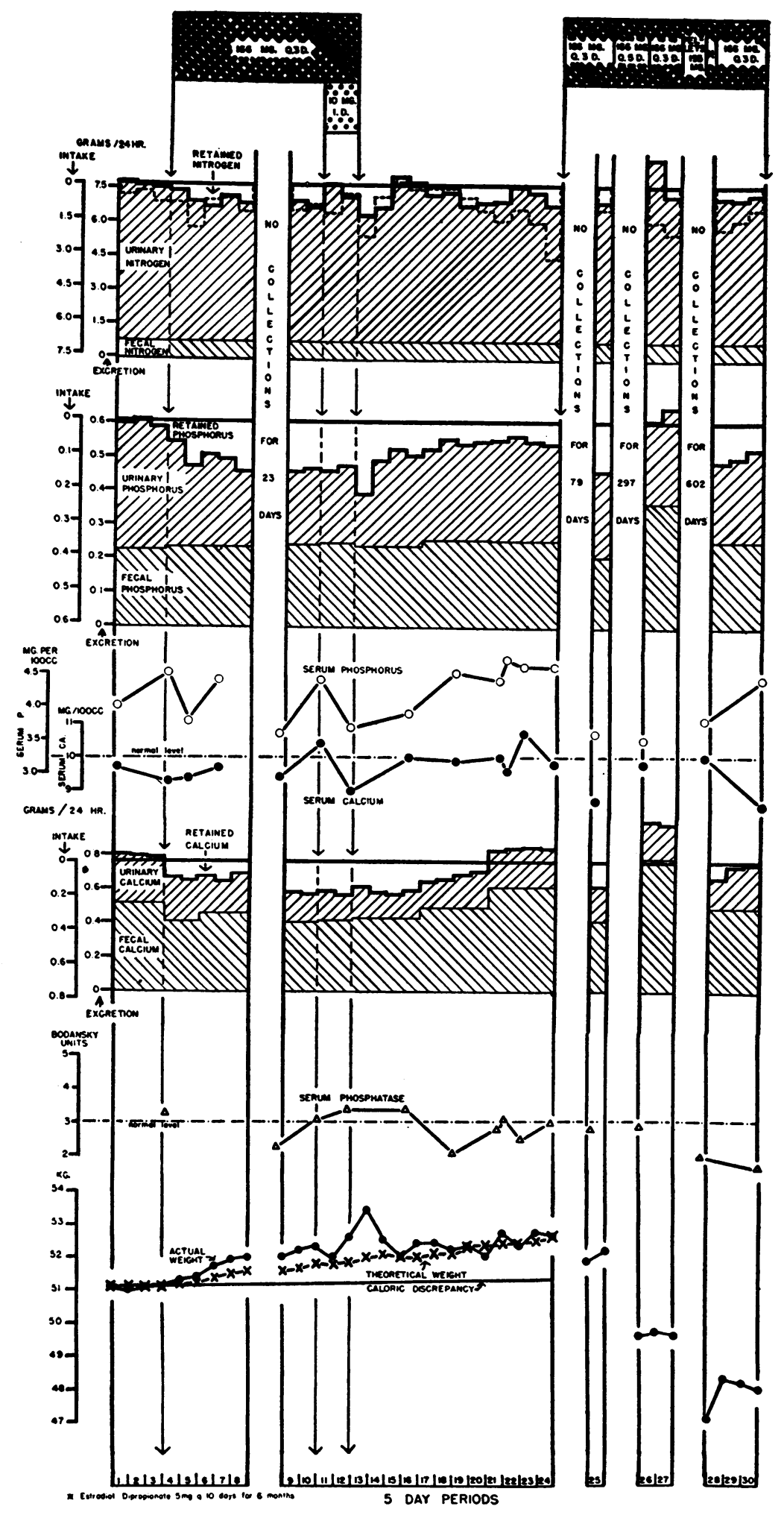

Fig. 1. Case 1 (F. F., M.G.H. 156453): Effect of Estradiol Benzoate on Nitrogen, Phosphorus, and Calcium Balances, on Serum 
Cushing's syndrome where, we believe, an excess of the adrenal cortical "sugar" or " $\mathrm{S}$ " hormone inhibits anabolism of protoplasm including bone matrix $(2,6)$; $(5)$ adaptation syndrome of Selye (7), where, we believe, the pathological physiology is the same as in Cushing's syndrome; (6) idiopathic osteoporosis, where the cause of the condition remains obscure; (7) acromegaly, where the cause may be the increase of pituitary hormone(s), or the secondary lack of gonadal hormones (8); and (8) the post-menopausal state, the commonest of all forms, where the difficulty is a deficiency in estrogen to stimulate the osteoblasts. Frequently 2 or more factors combine in one individual; thus, after an orthopedic operation (see Cases 7, 8, and 9, below) factors (1) and (5) probably both play a part.

\section{METABOLIC STUDIES}

For the methods employed in the accumulation, interpretation and presentation of these data, see (9). Case histories are abstracted in the appendix.

\section{A. Post-menopausal osteoporosis}

Case 1. Post-Menopausal Osteoporosis; Artificial Menopause; Estradiol Benzoate Therapy.

The metabolic data of Case 1 are shown in Figure 1 and Table I. The first part of the study, conducted in 5-day periods, consisted of: (1) three control periods; (2) five periods with estradiol benzoate $1.66 \mathrm{mgm}$. intramuscularly every 3 days; (3) twenty-three days with the same therapy at home; (4) two periods with the same therapy; (5) two periods with progesterone $10 \mathrm{mgm}$. intramuscularly daily in addition to the estradiol; and (6) twelve periods after the cessation of both medications. The patient was then discharged on estrogen therapy which was given continuously in varied dosage during the next 3 years; during this interval she was brought back to the metabolic ward for study ( 1 to 3 five-day periods) on 3 occasions.

The data (Figure 1) are self-explanatory. Attention should be called to: (1) nitrogen, phosphorus, and calcium equilibria during the control periods (1 to 3 ) ; (2) the high serum phosphorus level which tended to fall under estrogen therapy (less marked in this case than in the others [vide infra]); (3) the slight improvement in nitrogen balance under estrogen therapy; (4) the striking and growing decrease in calcium excretion, both fecal and urinary, with estrogen treatment and the gradual return ( 40 days) in calcium excretion to pre-treatment levels following cessation of estrogen therapy; (5) a decrease with estrogen treatment in the phosphorus excretion almost entirely confined to the urinary component, and reasonably proportional to the changes in the calcium and nitrogen metabolisms (see "Theoretical Nitrogen Balance"); (6) failure of the serum phosphatase level, the index of osteoblastic activity, to rise under estrogen therapy; (7) an increase in nitrogen, but not in calcium and phosphorus, excretions in periods 11 and 12 with progesterone therapy; and ( 8$)$ the tendency to retain extracellular fluids with estradiol therapy, as suggested by the increase in the actual weight above the theoretical weight.

The apparent discrepancy in the effect of estrogen on the calcium and phosphorus balances during periods 26 and 27 is probably to be explained by erroneously high fecal excretions resulting from too short a period of observation (9).

Case 2. Post-Menopausal Osteoporosis; Physiological Menopause; Question of Superimposed Atrophy of Disuse; Estradiol Benzoate Therapy.

The metabolic data of Case 2 are shown in Figure 2 and Table II. The study, conducted in 5-day periods, consisted of: (1) five control periods; (2) thirteen periods during which the patient received estradiol benzoate $3.32 \mathrm{mgm}$. intramuscularly every other day. In addition, during the 3 periods 14,15 , and 16 , testosterone propionate $25 \mathrm{mgm}$. were administered intramuscularly every other day.

The data in Case 2 confirm the main observations made on Case 1. The fall in the serum phosphorus level after estradiol medication was more pronounced than in Case 1 , and in addition there was a fall in the serum calcium level. Again the serum phosphatase level failed to rise with the improvement in the calcium balance. The duration of the testosterone propionate therapy was too short to judge its effect on the calcium balance; it brought about the expected increase in the nitrogen retention and rise in the urinary 17-ketosteroid excretion. The theoretical nitrogen balance based on the phosphorus balance after it had been corrected for the calcium balance agrees quite well with the measured nitrogen balance.

Calcium, Phosphorus, and Alkaline Phosphatase Levels, and on Body Weight in a Female Patient with Post-Menopausal OsteoPOROSIS

For discussion, see text.

The dotted line in the nitrogen metabolism data represents the "theoretical nitrogen balance." The fecal nitrogen was estimated as 10 per cent of the intake. The fecal calciumi and phosphorus values as charted are averages of $1,2,3$, or 4 five-day periods as follows: 1 through 3,4 through 5,6 through 8,9 through 10,11 through 12,13 through 16,17 through 20,21 through $24,25,26$ through 27,28 through 30 ; the individual values are given in Table I. 


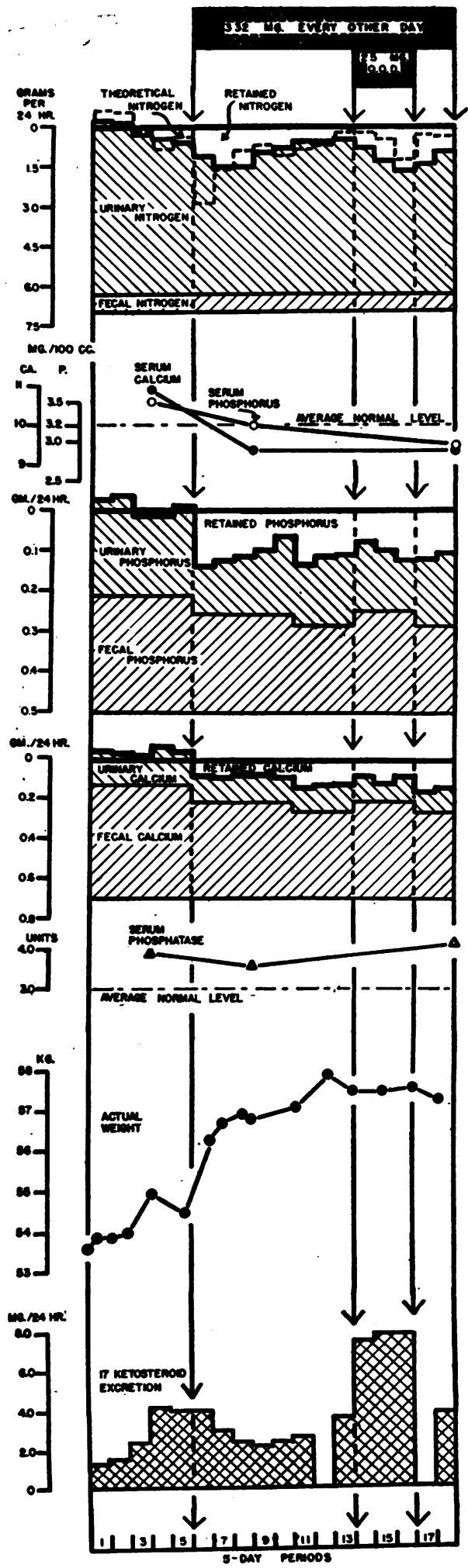

Fig. 2. Case 2 (E. P., M.G.H. 203540) : Effect of Estradiol Benzoate and Testosterone Propionate on
Case 3. Post-Menopausal Osteoporosis; Artificial Menopause; Estradiol Benzoate Therapy.

The metabolic data of Case 3 are shown in Figure 3 and Table III. The study, conducted in 5-day periods, consisted of : (1) four control periods; (2) nine periods in which $1.66 \mathrm{mgm}$. of estradiol benzoate were administered intramuscularly every 3 days; (3) ninety-three days at home on the same medication; (4) five periods on the same medication; (5) seven periods during which the estradiol dosage was doubled; and (6) five control periods of medication. During period 10 the patient was given in addition $10 \mathrm{mgm}$. of progesterone intramuscularly each day.

It will be noted in Figure 3 that the improvement in the calcium balance in this case following estradiol therapy was almost entirely due to the fall in the urinary calcium excretion. It is further suggested that the positive calcium balance tends to diminish with time (compare periods 14 to 18 with periods 11 to 13 ). Note, furthermore, that the calcium balance was not improved, and possibly reduced, when estradiol therapy was doubled in periods 19 through 25 . The fall in the serum phosphorus level with medication was especially striking in this case. The actual weight was greater than the theoretical weight during the therapy, which suggests retention of extracellular fluids.

Case 4. Post-Menopausal Osteoporosis; Artificial Menopause; Methyl Testosterone, Estradiol Benzoate and Pregnenolone Therapy.

The metabolic data of Case 4 are given in Figure 4 and Table IV. The study, conducted in 6-day periods, consisted of : (1) four control periods; (2) four periods on methyl testosterone, $40 \mathrm{mgm}$. by mouth daily; (3) five periods in which $1.66 \mathrm{mgm}$. of estradiol benzoate daily by injection were added to the methyl testosterone therapy; (4) five periods back on the methyl testosterone therapy alone; (5) four more control periods off medication; (6) three periods on pregnenolone, $30 \mathrm{mgm}$. intramuscularly daily; (7) four more control periods off medication; ( 8 ) five periods back on methyl testosterone, $40 \mathrm{mgm}$. by mouth daily with a change in the nitrogen and phosphorus intakes during the last 3 of these; and (9) one final period where the methyl testosterone therapy was increased to $100 \mathrm{mgm}$. by mouth daily. The urinary determinations were made on 3-day periods throughout.

In Figure 4 it should be noted first that the theoretical nitrogen balance is consistently less than the actual

Nitrogen, Phosphorus, and Calcium Balances, on Serum Calcium, Phosphorus, and Alkaline Phosphatase Levels, on Body Weight and on Urinary 17-Ketosteroid EXCRETION

For discussion, see text.

The fecal nitrogen was estimated as 10 per cent of the intake. The fecal phosphorus and calcium values as charted are averages of $2,3,4$, or 5 five-day periods as follows: 1 through 5,6 through 9,10 through 13, 14 through 16, 17 through 18 ; the individual values are given in Table II. 


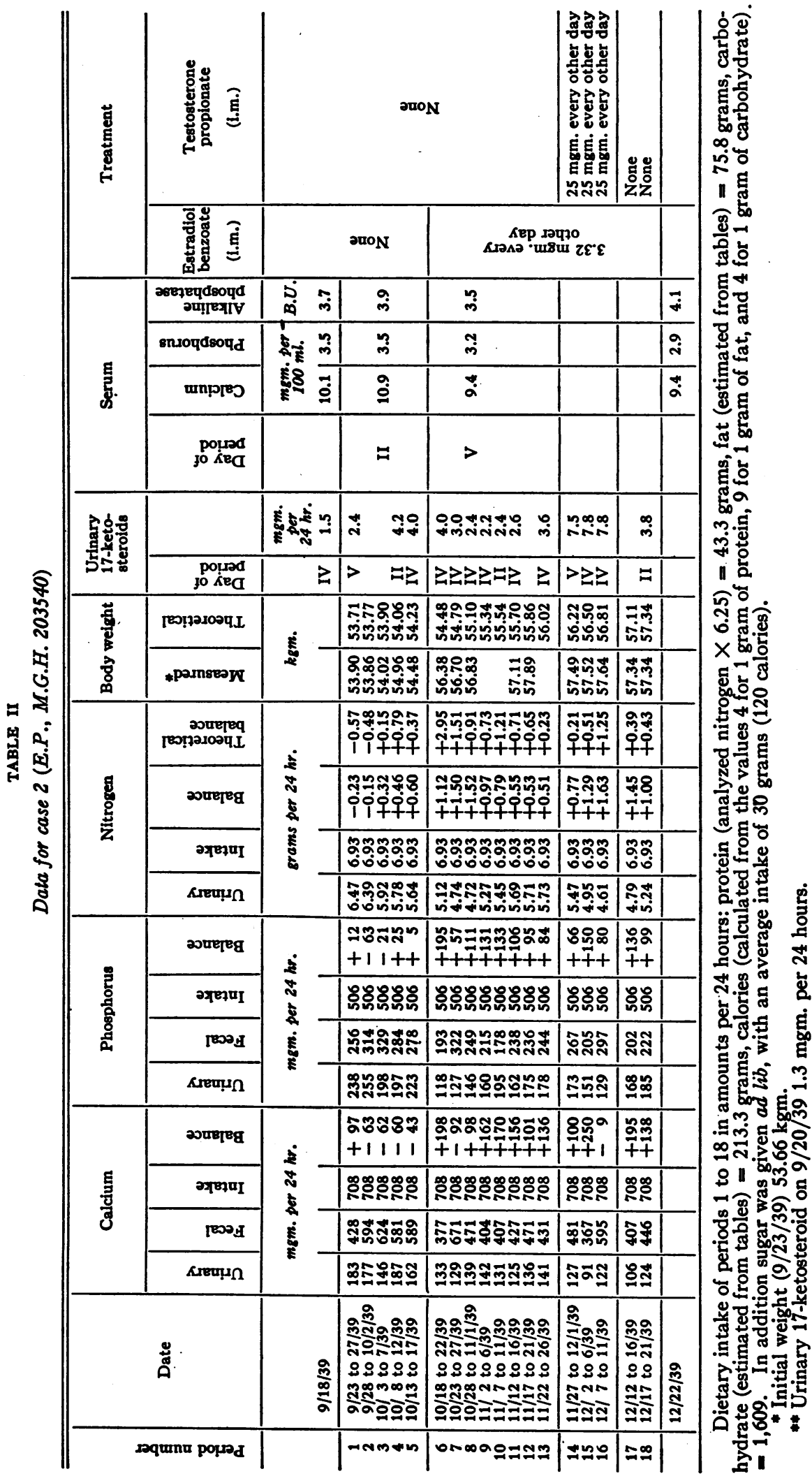




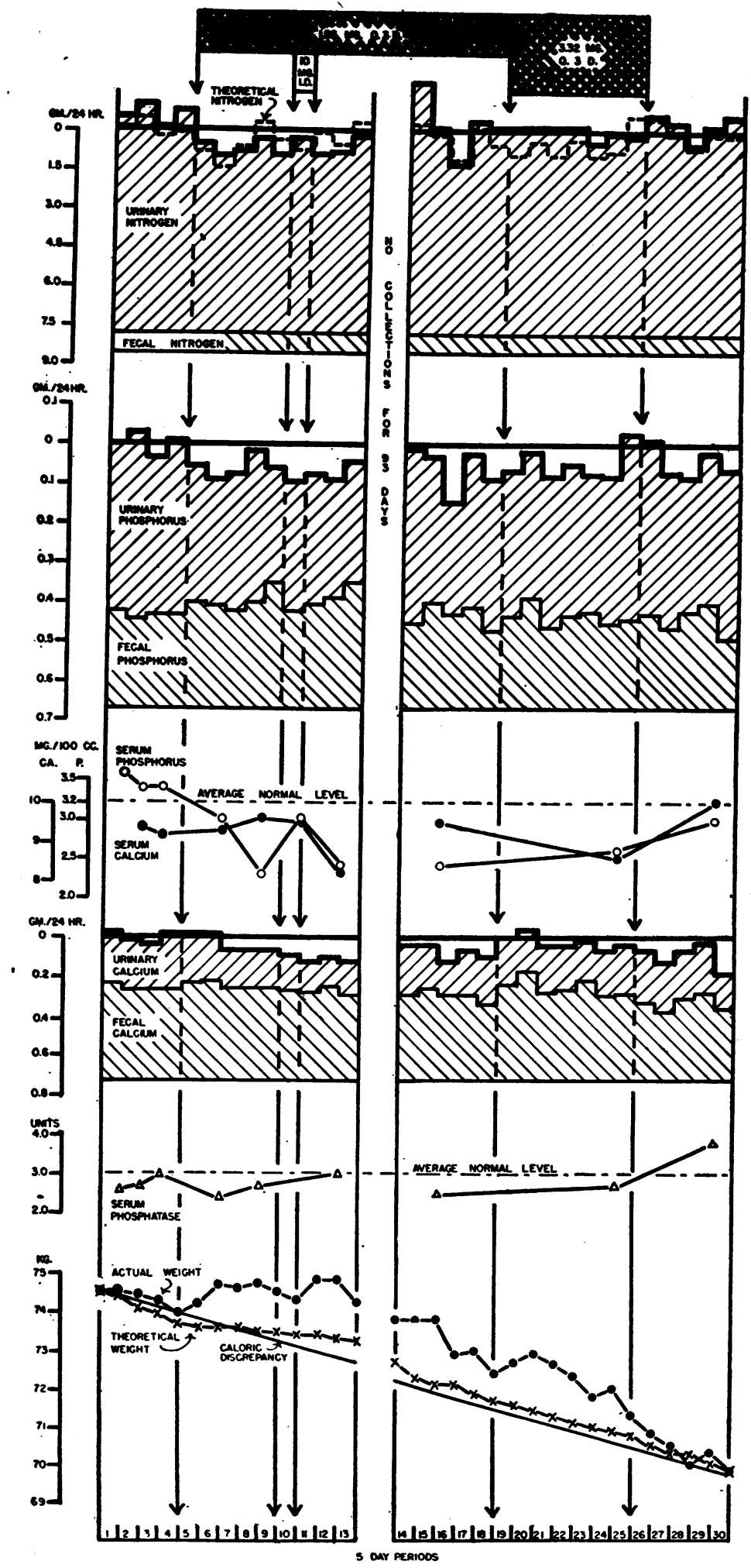

Fig. 3. Case 3 (A. M. R., M.G.H. 29358) : Effect of Estradiol Benzoate on Nitrogen, Phosphorus, and Calcium Balances, on Serum Calcium, Phosphorus, and Alkaline Phosphatase levers, and on Body Weight in a Female Patient with Post-Menopausal Osteoporosis

For discussion, see text. 
METABOLIC EFFECTS OF STEROID HORMONES IN OSTEOPOROSIS

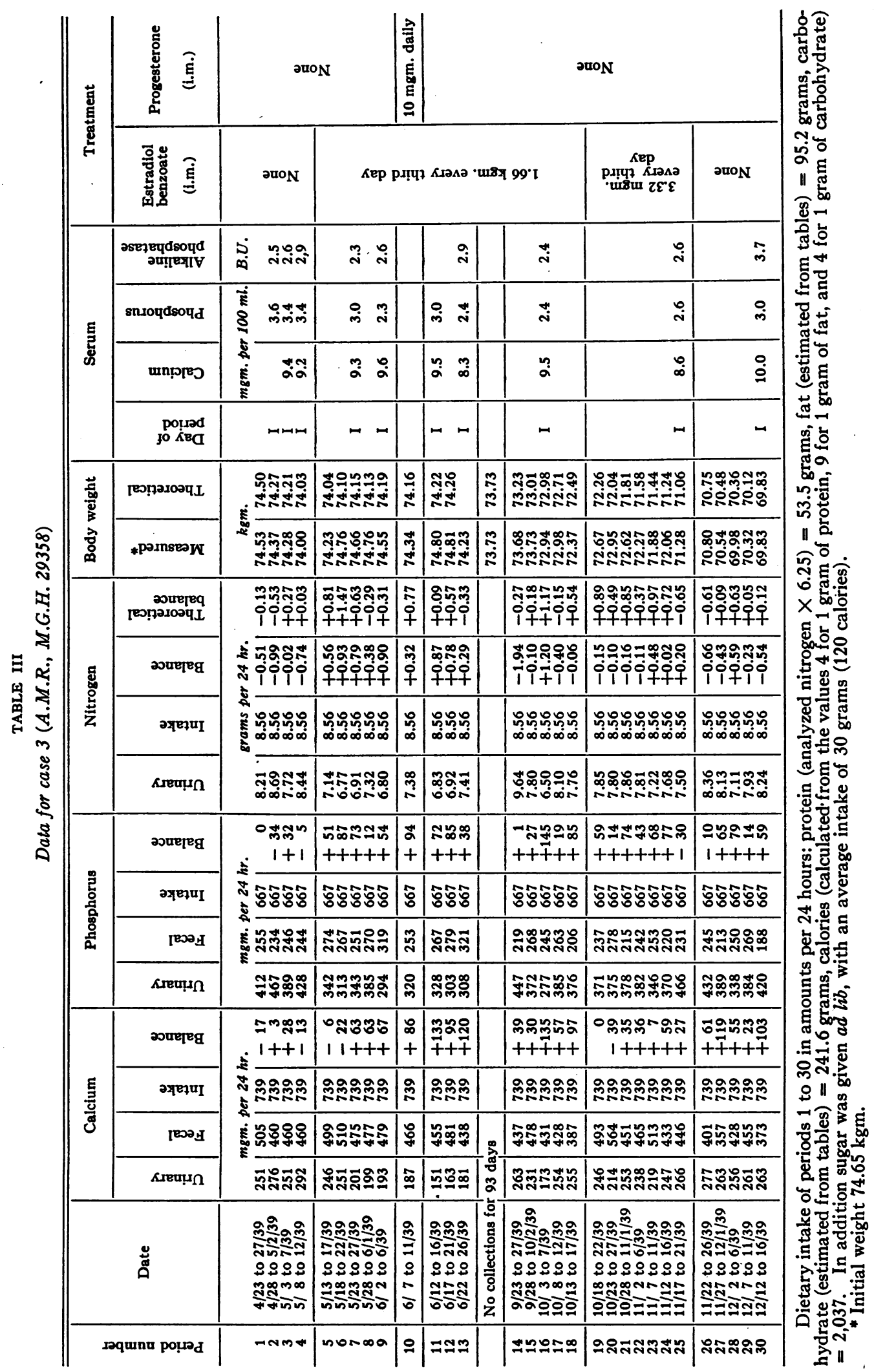




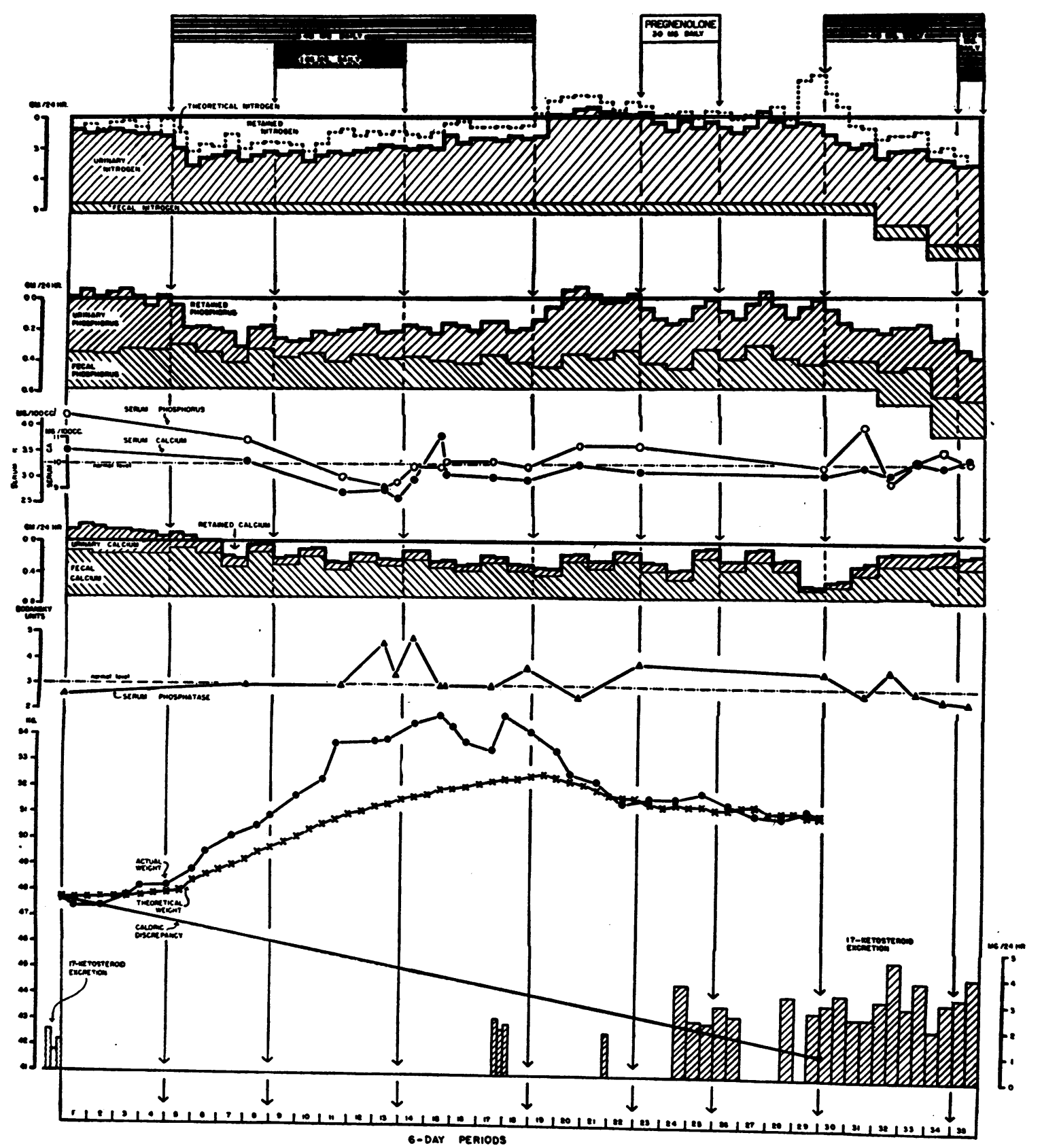

Fig. 4. Case 4 (R. W., M.G.H. 319940) : Effect of Methyl Testosterone Alone and in Combination with Estradiol Benzoate, and of Pregnenolone on Nitrogen, Phosphorus, and Calcium Balances, on Serum Calcium, Phosphorus, and Alraline Phosphatase Levels, on Body Weight, and on Urinary 17-Ketosteroid Excretion in a Female Patient with Post-Menopausal Osteoporosis

For discussion, see text.

nitrogen balance, which indicates that there is some constant error throughout. Part of the error may be in the fecal nitrogen excretion which was not analyzed, but taken as 10 per cent of the nitrogen intake. In the absence of analyzed values, it would have been preferable, and the discrepancy would have been cut down, had we used the value of 1.283 grams per 24 hours, the average fecal nitrogen value for adults regardless of intake (9). The major part of the discrepancy is probably to be attributed to errors in the intakes. The daily diet was 
METABOLIC EFFECTS OF STEROID HORMONES IN OSTEOPOROSIS

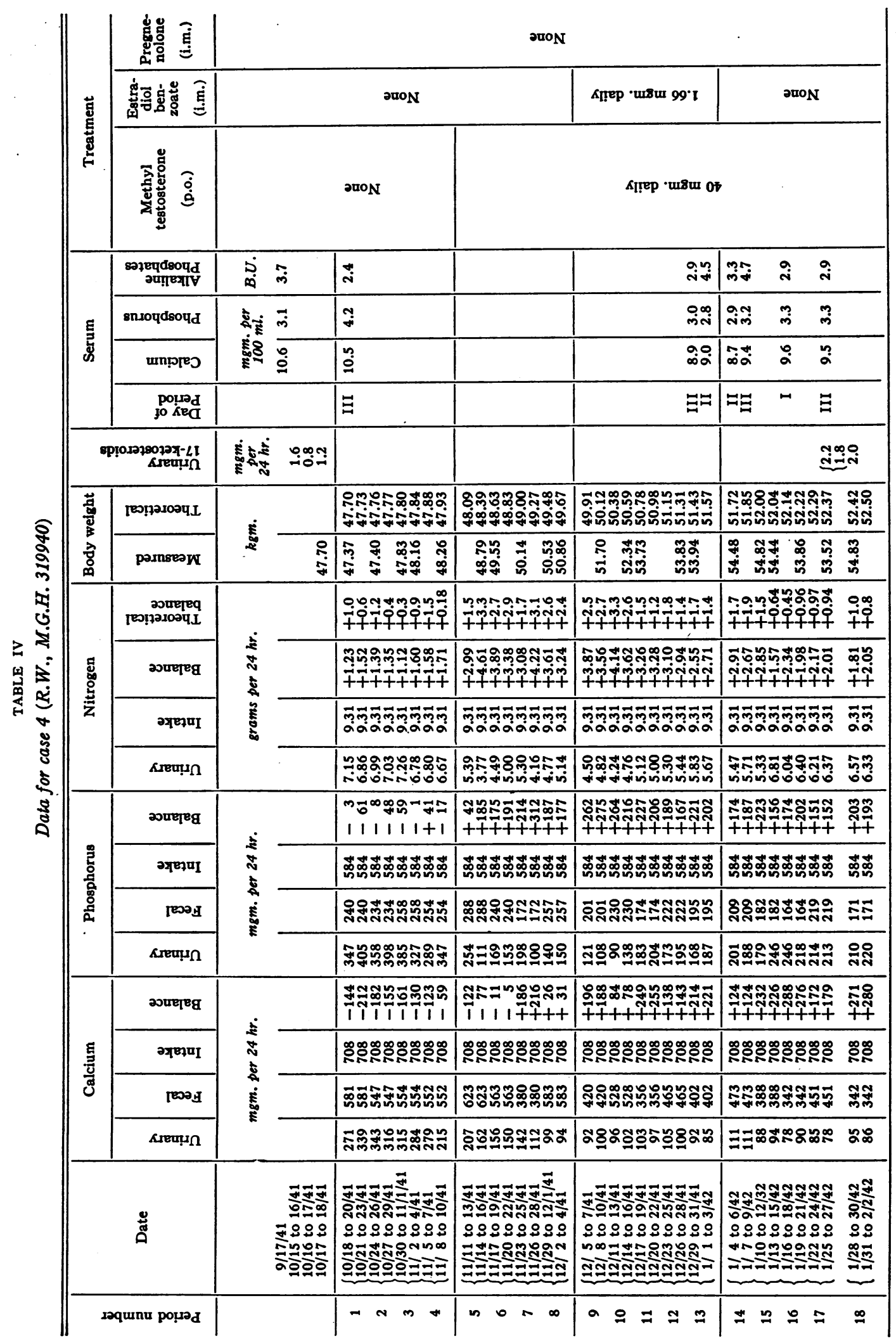




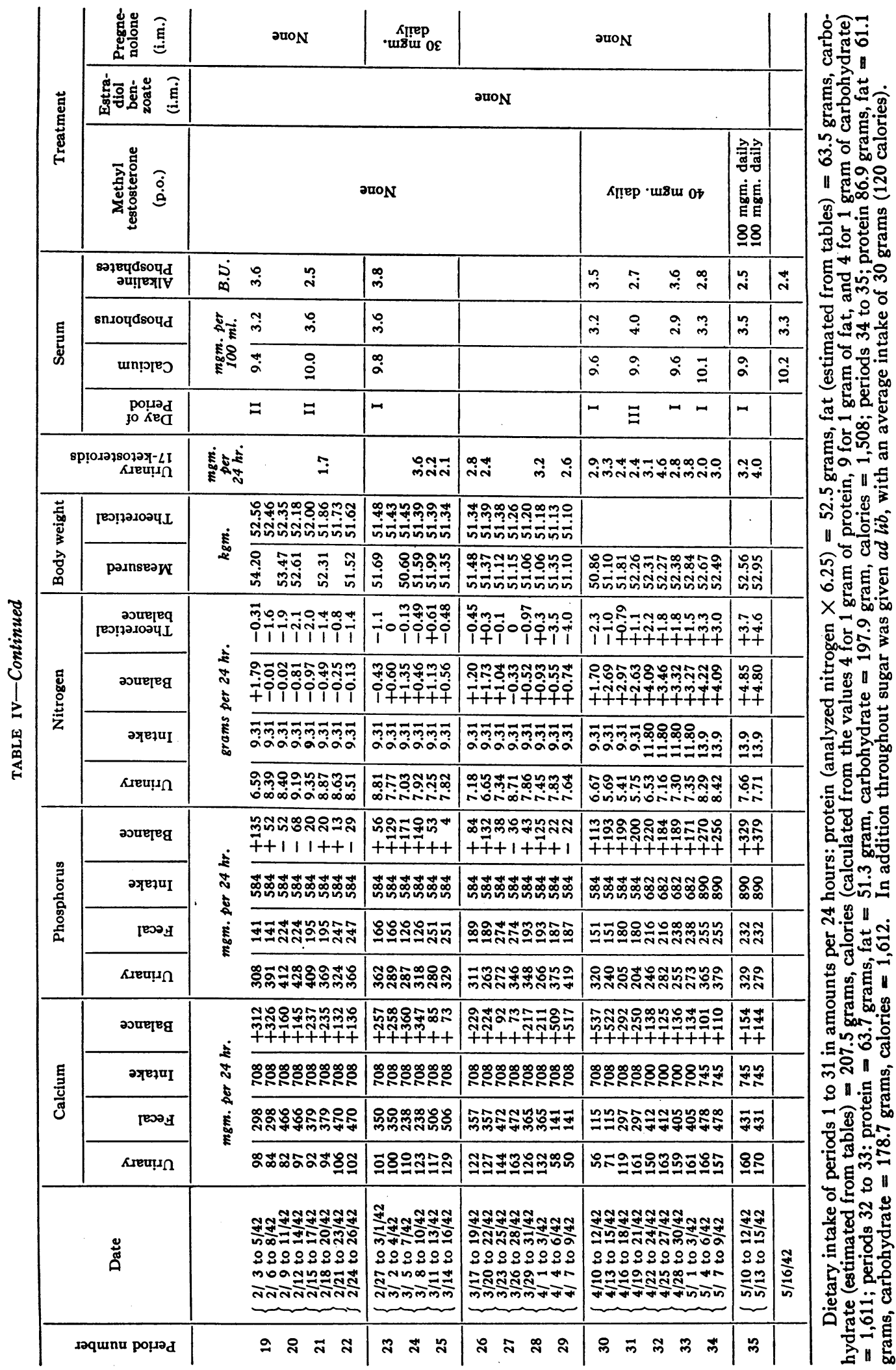


analyzed twice with the following results: analysis October 1941 : calcium $71 \mathrm{mgm}$., phosphorus $584 \mathrm{mgm}$., and nitrogen 9.31 grams; analysis February 2, 1944 : calcium $64 \mathrm{mgm}$., phosphorus $611 \mathrm{mgm}$., and nitrogen 8.40 grams. Figure 4 was constructed from the analysis of 1941 ; had it been constructed from the analysis of 1944, the discrepancy would have been almost eliminated. Thus, if one recalculates on the basis of the 1944 analysis the theoretical nitrogen balance of period $4 \mathrm{~b}$, and in addition uses the value of 1.283 grams for the fecal nitrogen instead of 10 per cent of the intake, one obtains the values +0.65 and +0.45 grams for the theoretical and actual nitrogen balances, respectively, in contrast to the values of +0.18 and +1.71 grams. Since the above discrepancy is fairly constant, it does not affect the trends induced by treatment.

Figure 4 is self-explanatory. To be noted are: (1) the decrease in the nitrogen, phosphorus, and calcium excretions with methyl testosterone therapy, and the rebound of nitrogen and phosphorus excretions on cessation of therapy; (2) the fact that the fecal, as well as the urinary, excretions of both calcium and phosphorus were reduced under methyl testosterone therapy; (3) the fact that there was not an immediate rebound of the calcium excretion following cessation of methyl testosterone therapy; (4) the further improvement in the calcium balance, but not in the nitrogen balance, when estradiol benzoate therapy was added to the methyl testosterone therapy (periods 9 to 13); (5) the fall in serum phosphorus level with methyl testosterone and especially with estradiol benzoate therapy; (6) the definite tendency of the serum calcium level to parallel the serum phosphorus level (see also Figure 2); and (7) the failure of the serum phosphatase level to show a significant change. The effect of the pregnenolone therapy is inconclusive; it did not significantly affect the very low 17-ketosteroid excretion. No explanation is forthcoming in periods 29 and 30 for the low fecal calcium excretions not associated with low nitrogen and phosphorus excretions; as a result, the data during periods 30 through 36 are difficult to interpret. The actual and theoretical weight curves suggest that there was retention of extracellular fluid with methyl testosterone therapy which was augmented when estradiol benzoate therapy was added. Pregnenolone therapy had a minimal effect on extracellular fluid retention.

Case 5. Post-Menopausal Osteoporosis; Artificial Menopause; Paget's Disease; Diethylstilbestrol and Progesterone Therapy.

The metabolic data of Case 5 are given in Figure 5 and Table V. The study, conducted in 6-day periods, consisted of : (1) three control periods; (2) five periods on $1 \mathrm{mgm}$. of diethylstilbestrol by mouth daily; (3) seven periods on $15 \mathrm{mgm}$. of diethylstilbestrol by mouth daily, with an increase in the diet in the last 3 of these; (4) six periods with the same dosage of diethylstilbestrol in which progesterone by injection was given in addition (25 $\mathrm{mgm}$. daily for the first 4 of these periods, and $100 \mathrm{mgm}$. daily for the last 2); and (5) three periods on $15 \mathrm{mgm}$. of diethylstilbestrol daily alone.

This patient was selected for the study not only because she had marked osteoporosis from an artificial menopause 30 years before, but because she had, in addition, Paget's disease. The primary pathologic process of the Paget's disease, bone destruction, was not being responded to with the usual amount of increased bone formation because of the menopause (4). Therefore, it was thought that any action of estrogen to stimulate bone formation would be magnified in this patient.

Figure 5 is self-explanatory. To be noted are: (1) the markedly negative calcium and phosphorus balances during the control periods; (2) the marked improvement of these balances with $1 \mathrm{mgm}$. of diethylstilbestrol daily; (3) the further improvement with $15 \mathrm{mgm}$. of diethylstilbestrol daily; (4) the lack of effect of progesterone on the calcium and phosphorus balances; (5) the high serum phosphorus before treatment; (6) the tendency of the serum phosphorus to fall during treatment; (7) the failure of the serum phosphatase to rise with improvement of the calcium balance; $(8)$ the tendency of the 17 -ketosteroid excretion to rise with progesterone; (9) the failure of the "11-oxysteroid" excretion 4 to fluctuate outside of the normal range with therapy; (10) the striking fall 5 in the urinary follicle-stimulating hormone (FSH) excretion with diethylstilbestrol therapy; and (11) the subsequent rise in the FSH excretion when progesterone therapy was superimposed on the diethylstilbestrol therapy. The increase in the positive nitrogen balance and the increase in weight during periods 22 to 24 may be indications that progesterone was acting unfavorably on the nitrogen balance (12). Not explained is the rise in FSH excretion in periods 23 and 24.

\section{B. Senile osteoporosis}

Case 6. Senile Osteoporosis in a Male of 72; Testosterone Propionate and Estradiol Benzoate Therapy.

The metabolic data of Case 6, which comprise studies done on 290 of 530 consecutive days, are shown in Figure 6 and Table VI. The study, conducted in 5-day periods, consisted of: (1) five control periods; (2) five periods on testosterone propionate, $25 \mathrm{mgm}$. by injection daily; (3) five periods in which estradiol benzoate $1.66 \mathrm{mgm}$. by injection on alternate days was added to the testosterone propionate therapy; (4) five periods back on testosterone propionate alone; (5) seven control periods off all medication; (6) five periods on estradiol benzoate $1.66 \mathrm{mgm}$. by injection twice daily; (7) ten days without collections on the same medication; (8) two more periods on the same medication; (9) ninety-three days at home on estradiol benzoate $3.32 \mathrm{mgm}$. by injection 3 times

4 These observations were carried out by Dr. Nathan B. Talbot with his method (10). The normal range is 0.10 to $0.35 \mathrm{mgm}$. per 24 hours.

5 The level fell from $200-300$ units per day to less than 6 units per day. Normal range of FSH excretion is 6 to 50 mouse units per day (11). 


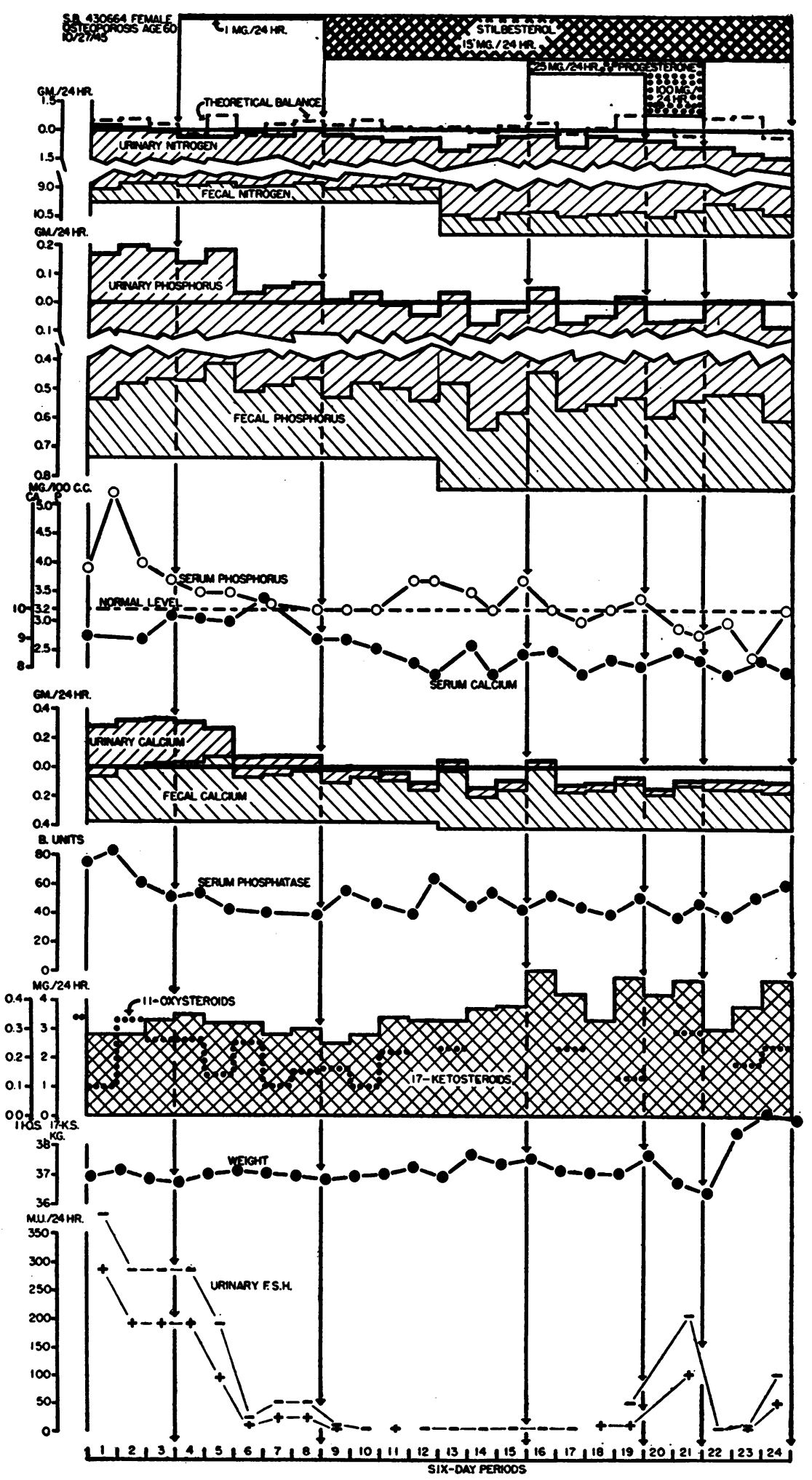

Fig. 5. Case 5 (S. B., M.G.H. 430664) : Effect of Diethylstilbestrol Alone and in Combination with Progesterone on Nitrogen, Phosphódus, and Calcium Balances, on Serum Calcium, Phosphorus, and Alkaline Phosphatase Levels, on Body Weight, and on Urinary 17-Ketosteroid, "11-Oxysteroid," and Follicle-Stimulating Hormone Excretion in a Female Patient with Post-Menopausal Osteoporosis and Paget's Disease

For discussion, see text. 
METABOLIC EFFECTS OF STEROID HORMONES IN OSTEOPOROSIS

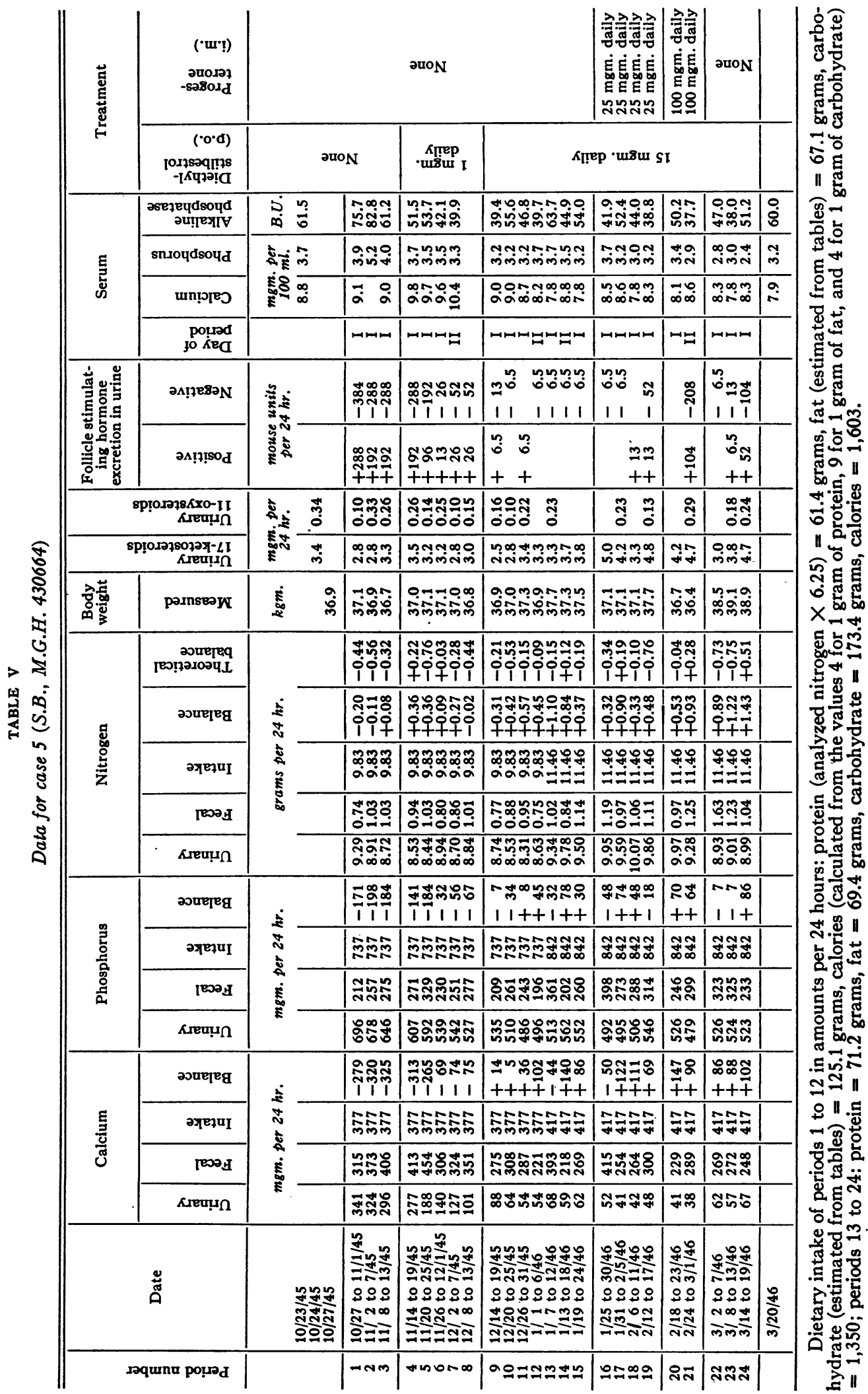




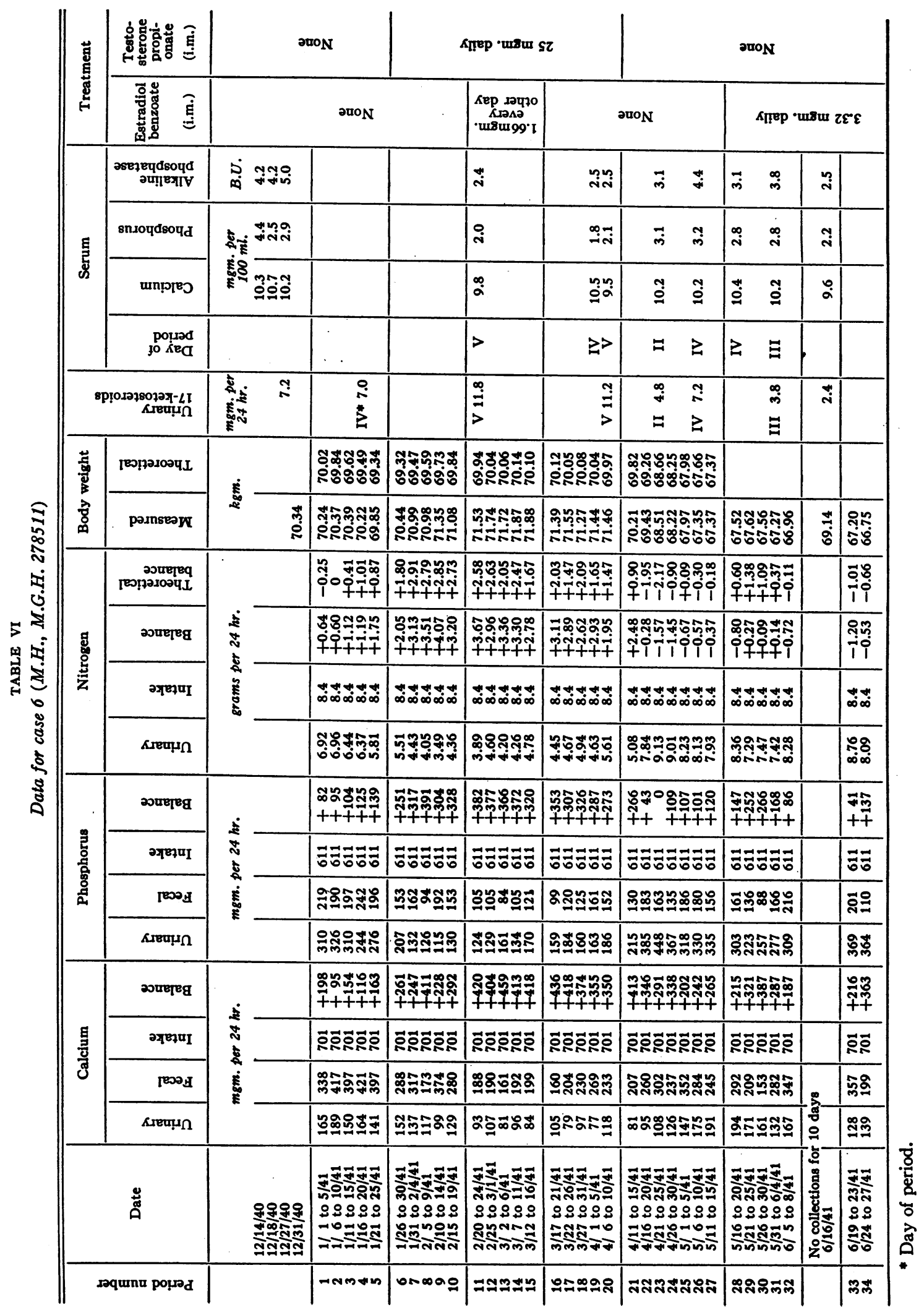


METABOLIC EFFECTS OF STEROID HORMONES IN OSTEOPOROSIS

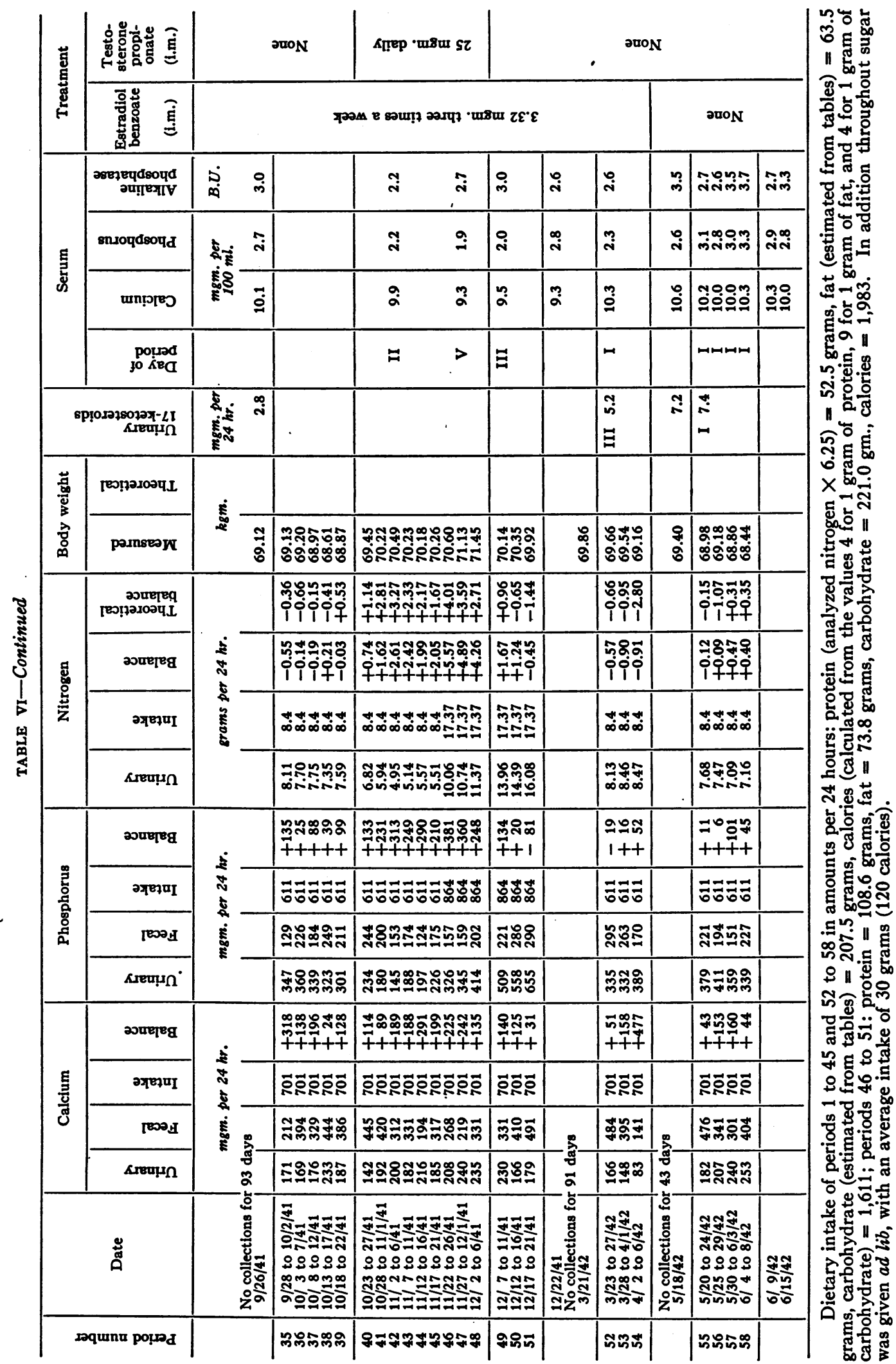




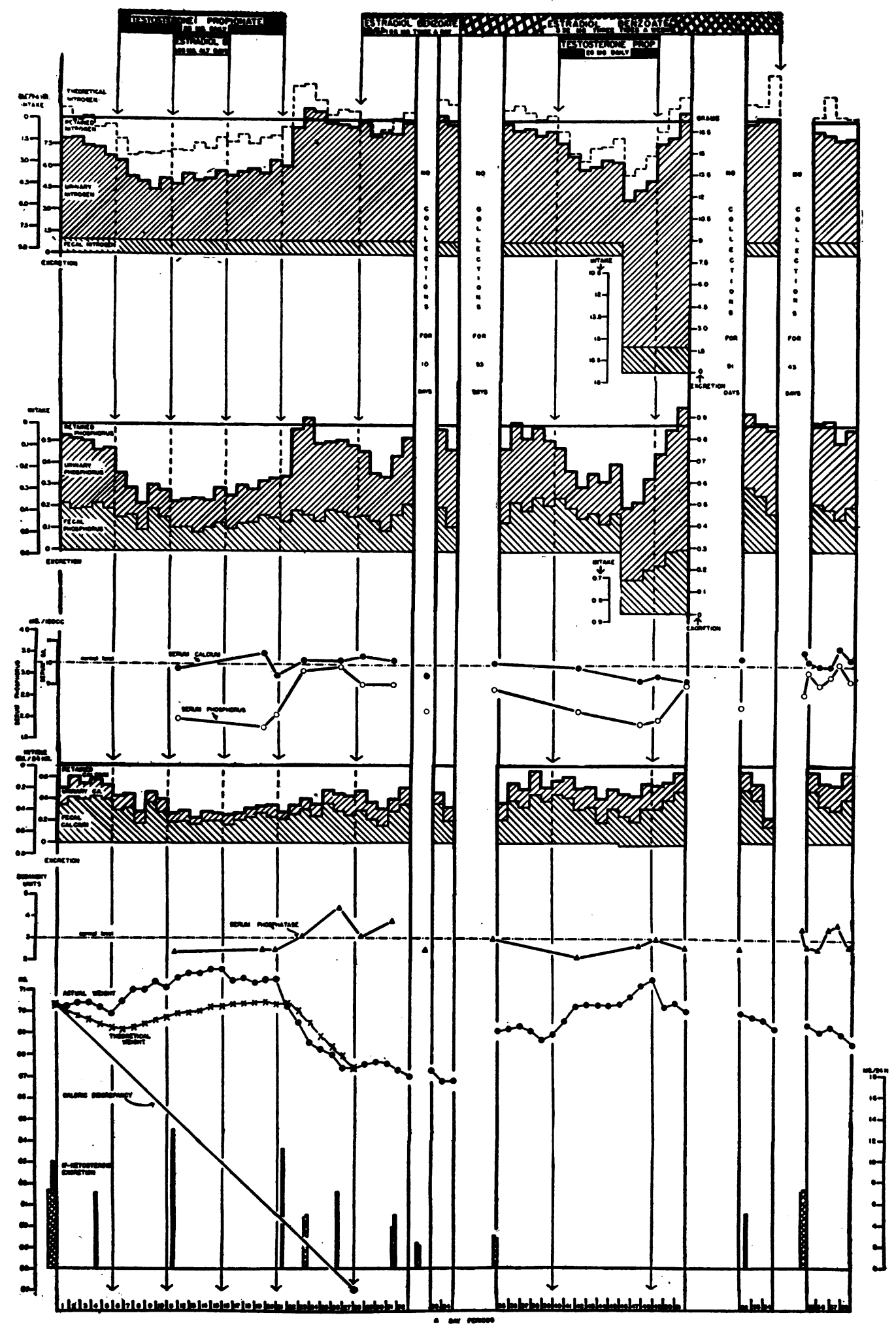

Fig. 6. Case 6 (M. H., M.G.H. 278511) : Effect of Testosterone Propionate Alone and in Combination with Estradiol Benzoate and vice versa on Nitrogen, Phosphorus, and Calcium Balances, on Serum Calcium, Phosphorus, and Alkaline Phosphatase levels, on Body Weight, and on Urinary 17-Ketosteroid Excretion in a Male Patient with Senile OsteoPOROSIS

For discussion, see text. 


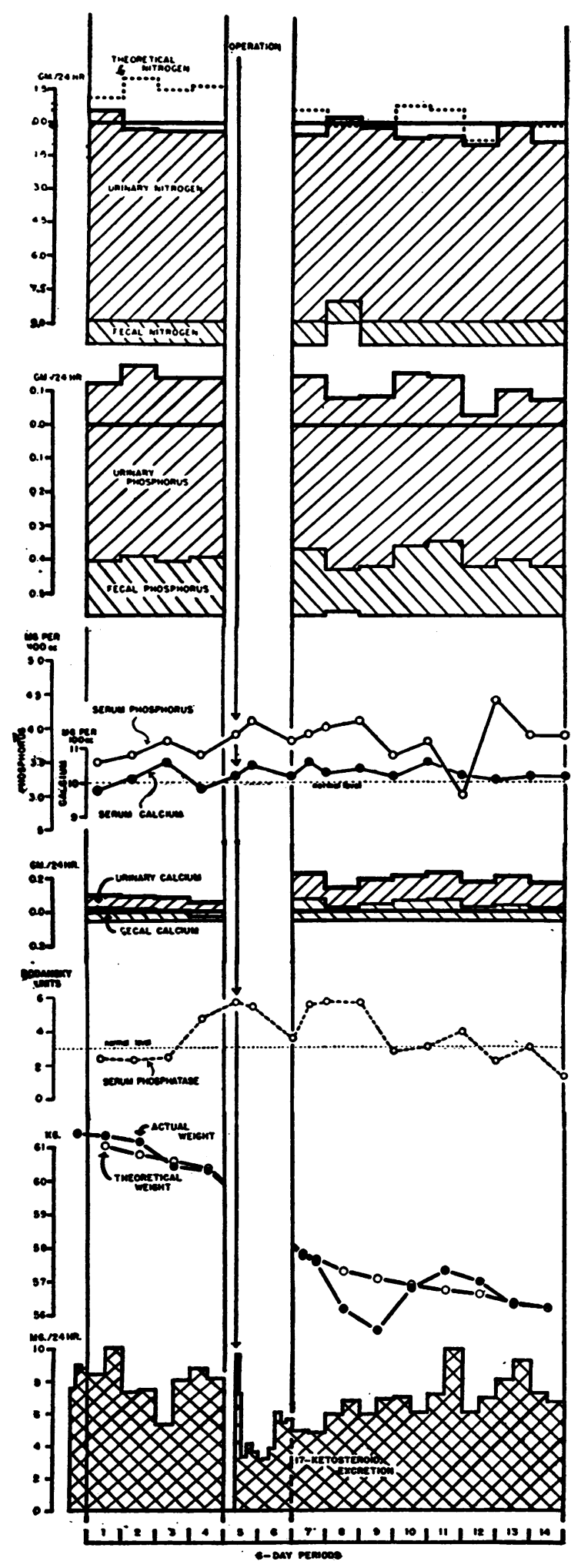

Fig. 7. Case 7 (E. S., M.G.H. 360207) : Nitrogen, Phosphorus, and Calcium Balances; Serum Cal- a week; (10) five periods on the same therapy; (11) nine periods in which testosterone propionate $25 \mathrm{mgm}$. intramuscularly daily was added to the estradiol benzoate therapy, during the last 3 of which periods the intakes of nitrogen and phosphorus were markedly increased; (12) three periods on the same diet and the same estradiol benzoate therapy but off testosterone propionate therapy; (13) ninety-one days at home on the same estradiol benzoate therapy; (14) three periods on the original diet without change in the estradiol therapy; (15) forty-three days at home off all medication; and finally (16) four control periods on the original diet without medication.

Figure 6 is self-explanatory. The observations as a whole confirm those noted in Cases 1 to 4 with postmenopausal osteoporosis.

Again, as in Case 4, the theoretical nitrogen balance as charted is consistently less positive than the actual nitrogen balance which suggests some constant error. This discrepancy is probably to be attributed to errors in the intakes and to estimation of the fecal nitrogen as 10 per cent of the nitrogen intake (see discussion under Case 4). Case 6 received the same diet as Case 4; this diet was analyzed twice with the results given in the discussion under Case 4. Figure 6 was constructed from the analysis of 1941; had it been constructed from the analysis of 1944 , as is Table V, the discrepancy would have been almost eliminated. Thus, if one recalculates on the basis of the 1944 analysis, the theoretical nitrogen balance of period 5, and in addition uses the value of 1.283 grams for the fecal nitrogen instead of 10 per cent of the intake, one obtains the values +0.87 and +1.30 grams for the theoretical and actual nitrogen balances, respectively, in contrast to the values of +0.41 and +2.21 grams. As was pointed out in connection with Case 4, since the above discrepancy is fairly constant, it does not affect the trends induced by treatment.

To be noted especially in Figure 6 are: (1) the marked reduction in nitrogen, phosphorus, and calcium excretions with testosterone therapy; (2) the lack of rebound in the calcium excretion as opposed to nitrogen and phosphorus following cessation of testosterone therapy; (3) the further reduction in the phosphorus and especially in the calcium excretion, but not in the nitrogen excretion, when estradiol benzoate therapy was added to testosterone propionate therapy (periods 16 to 20 ) ; (4) the improvement in all 3 balances when testosterone propionate was added to estradiol benzoate therapy (periods 40 to 45); (5) reduction in the fecal as well as the urinary calcium and phosphorus excretions by both testosterone propionate and estradiol benzoate therapy; (6) the effect of both testosterone propionate and estradiol benzoate therapy in lowering the serum phosphorus level; (7) the failure of marked increases in the nitrogen and phosphorus bal-

cium, Phosphorus, and Alkaline Phosphatase Levels; Weight; aNd URINARY 17-Ketosteroid Excretion in a Female Patient with Osteoporotic Process InDUCED BY OPERATION AND IMMOBILIzation

For discussion, see text. 


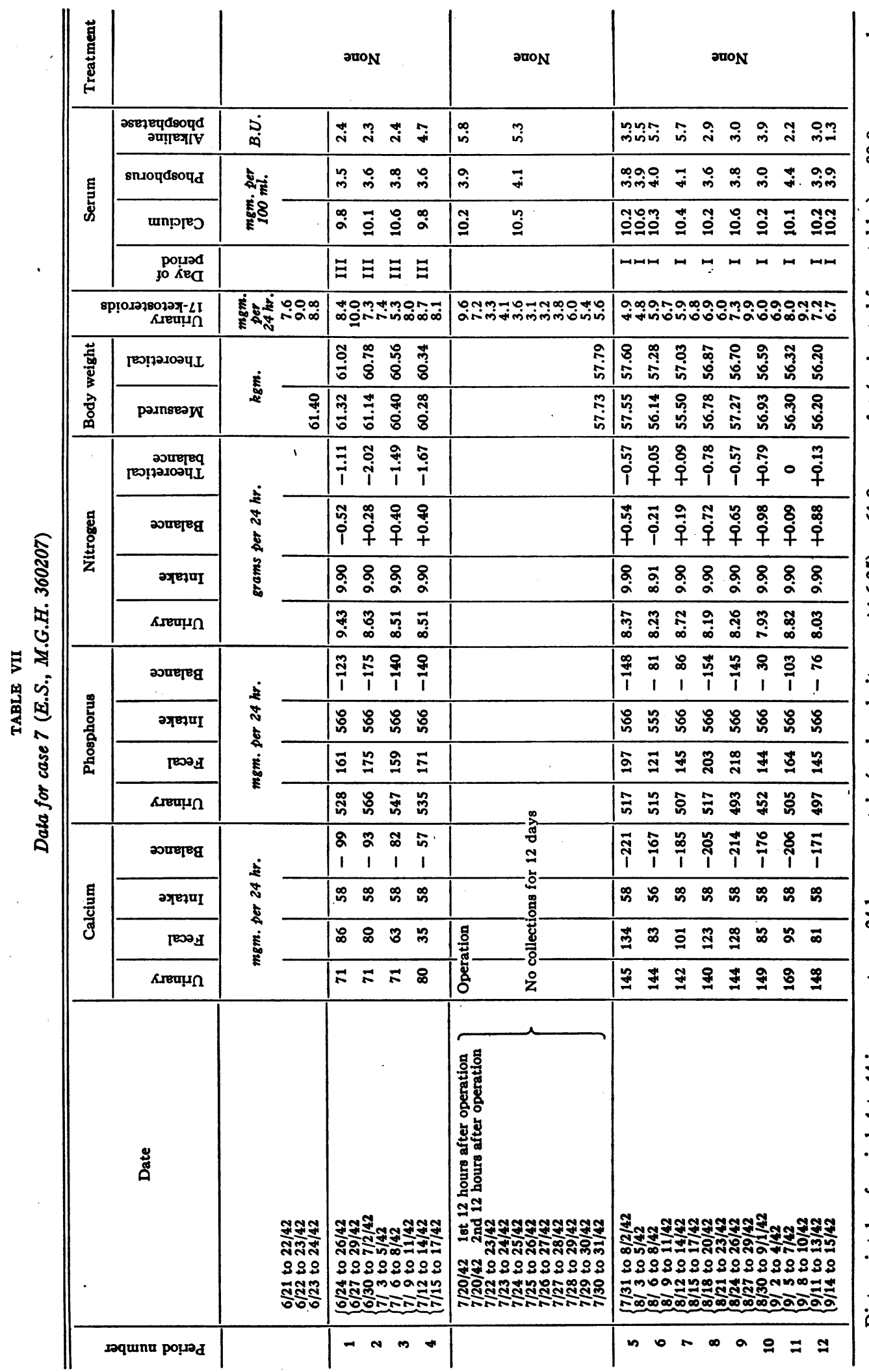




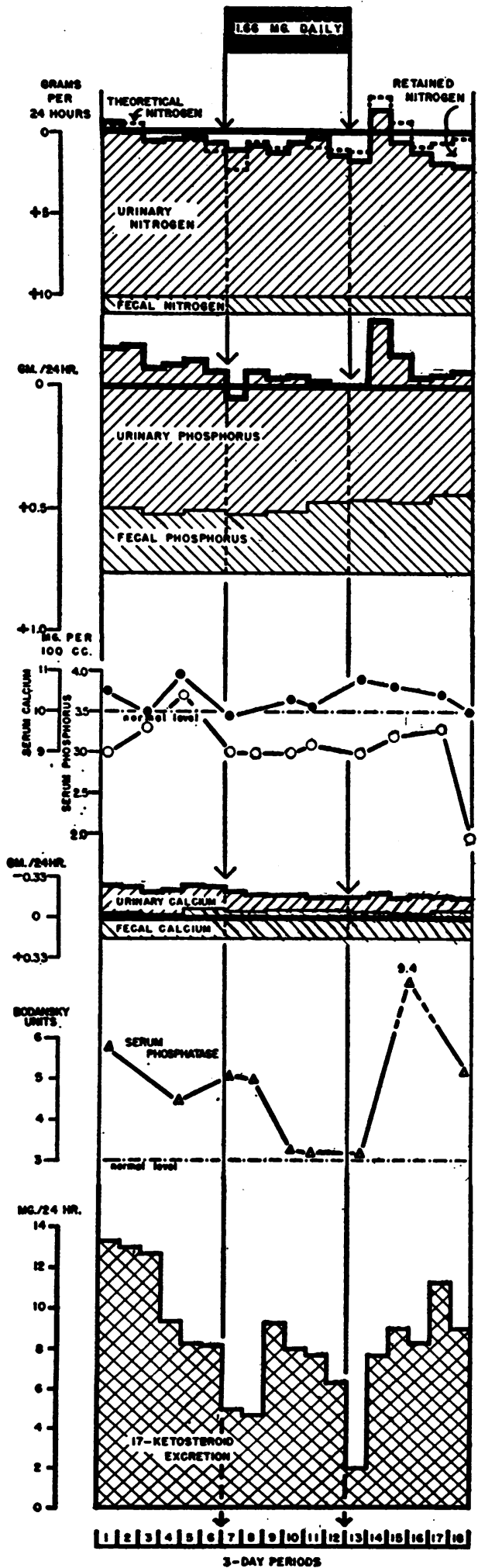

Fig. 8. CASE 8 (H. D., M.G.H. 382395) : Effect of Estradiol Benzoate on Nitrogen, Phosphorus, and ances by increased diet to affect the calcium balance (periods $46,47,48)$; (8) the absence of any significant change in the serum phosphatase and calcium levels; (9) the fall in the urinary 17-ketosteroid level with estradiol benzoate therapy; and (10) the tendency to accumulate extracellular fluid during both testosterone propionate and estradiol benzoate therapy as suggested by the theoretical weight curves, with a prompt loss following the cessation of therapy.

\section{Osteoporosis resulting from disuse and/or adaptation syndrome}

Case 7. "Normal" Female; Effect of Orthopedic Operation; No Specific Therapy.

The metabolic data of Case 7 are shown in Figure 7 and Table VII. Throughout the entire experiment the patient was on a constant, neutral-ash, low calcium diet, except for the immediate post-operative period. She was up and active during the pre-operative period, and immobilized in a cast from the foot to the hip after operation. She underwent an arthrodesis of the right foot on the second day of period 5; there were no analyses for metabolic data during periods 5 and 6 , but the 17-ketosteroid excretion was followed.

During the 4 control periods the patient was in negative calcium and phosphorus balance; the former was of the order of magnitude one would expect with patients on this diet (13). As expected, there was a marked increase in the calcium excretion after the operation, which persisted unabated to the end of the investigation (58 days after the operation) (14). The increase in calcium excretion was not entirely in the urine. The 17 -ketosteroid excretion was normal pre-operatively, which confirms the contention that she was not debilitated; it rose immediately after operation, and then fell decidedly below the preoperative level for about 20 days. The pattern of response was thus similar to that encountered following any traumatizing event (15). The marked elevation in 17ketosteroid excretion in period 11 coincided with the patient being allowed up in a wheel chair (16).

Periods 7 through 14 in this untreated case serve as a control for similar studies in Cases 8 and 9, who received estradiol therapy during the post-operative period (Figure 10).

Case 8. Multiple Traumatic Fractures with Operative Reduction of One in a Previously "Normal" Male; Effect of Estradiol Benzoate Therapy.

The metabolic data of Case 8 are shown in Figure 8 and Table VIII. The study, conducted in 3-day periods, consisted of; (1) six control periods; (2) six periods in which $1.66 \mathrm{mgm}$. of estradiol benzoate was given

Calcium Balances; on Serum Calcium, Phosphorus, and Alkaline Phosphatase Levels; and on Urinary 17-Ketosteroid Excretion in a Male Patient with Osteoporotic Process Induced by Multiple Fractures, Operation, and Immobilization

For discussion, see text. 


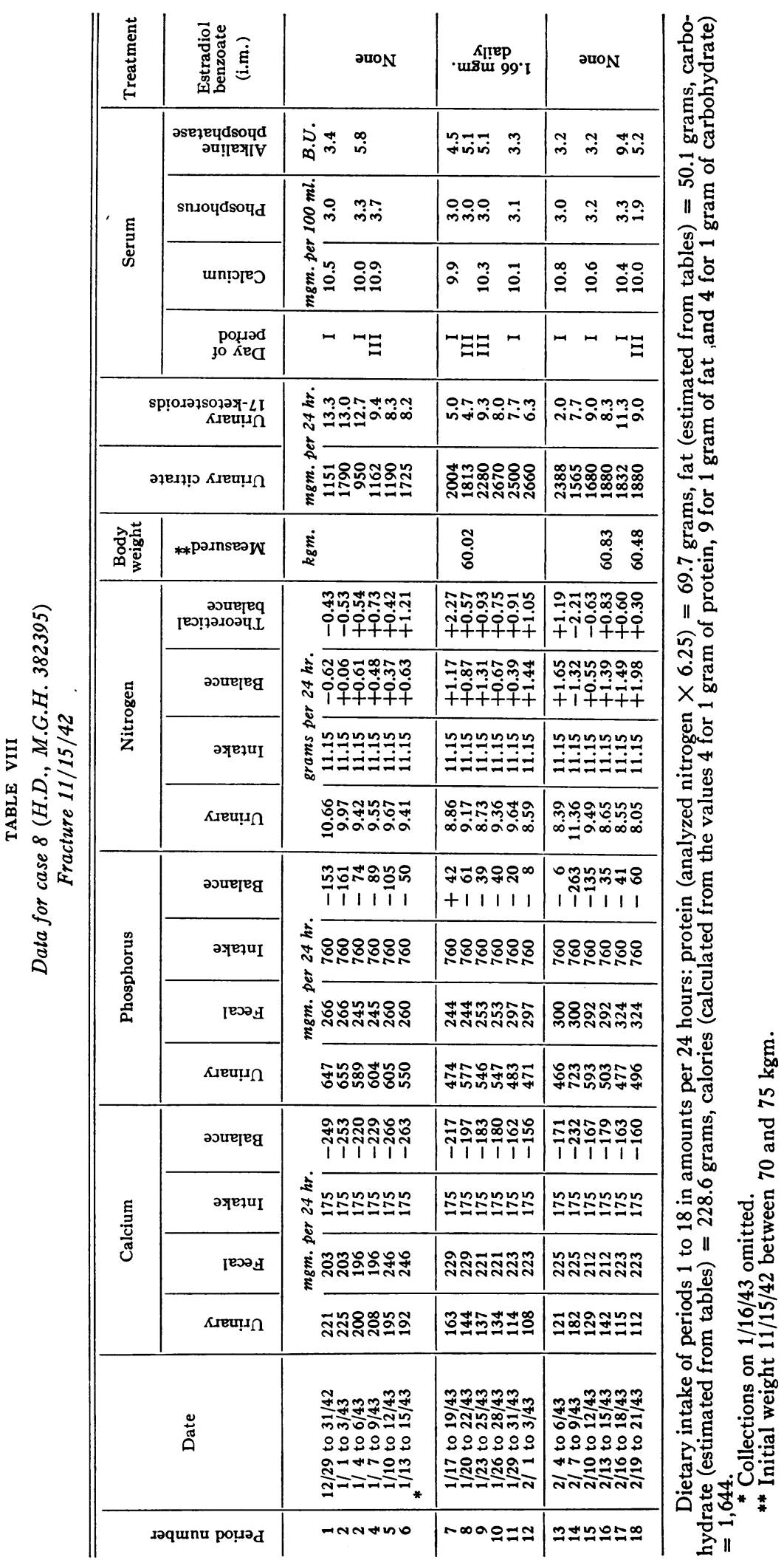




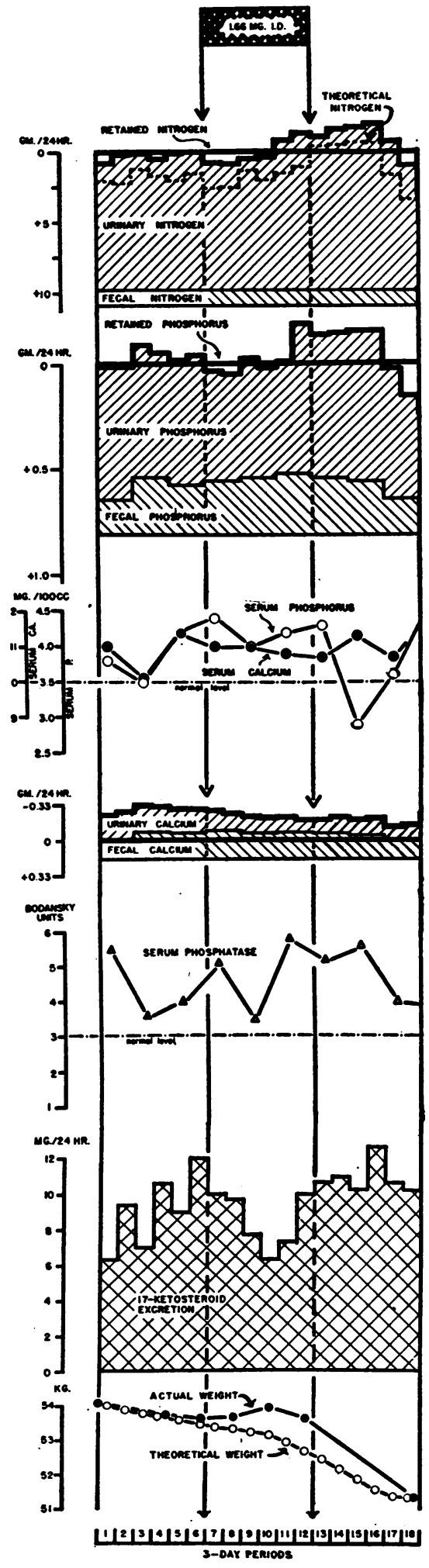

Fig. 9. CASE 9 (C. M., M.G.H. 348774) : EFFect of Estradiol Benzoate on Nitrogen, Phosphorus, and daily by injection; and (3) six post-treatment control periods. The stool periods were analyzed 2 at a time.

Figure 8 is self-explanatory. The most important observations concern the calcium metabolism; these are better shown in Figure 10 and will be discussed below. Again, there was a fall in the serum phosphorus, and, if anything, a fall in the serum phosphatase. Of interest is the fall in 17-ketosteroids in period 13 , followed by the rise in urinary nitrogen, phosphorus, and calcium in period 14; we believe these to be connected though unexplained phenomena.

Case 9. Bone Grafting Operation in an Ununited Femur of an Otherwise "Normal" Male; Effect of Estradiol Benzoate Therapy.

The metabolic data of Case 9 are shown in Figure 9 and Table IX. The study, conducted in 3-day periods, consisted of: (1) six control periods; (2) six periods in which $1.66 \mathrm{mgm}$. of estradiol benzoate was given daily by injection; and (3) six post-treatment control periods. The stool periods were analyzed 2 at a time.

Figure 9 is self-explanatory. The theoretical nitrogen balance shows a constant deviation from the measured nitrogen balance which suggests some constant error (vide supra). The calcium data, as in Case 8 , are better shown in Figure 10, and will be discussed below. It should be noted that the serum phosphorus in this case, as opposed to all of the other cases, did not fall during estradiol therapy. The 17-ketosteroid excretion showed a tendency to fall during the estradiol benzoate therapy, which is also somewhat suggested in Figure 7.

\section{Further analysis of calcium data of Cases 7, 8, and 9}

In Figure 10 the calcium data of Cases 8 and 9 with estradiol benzoate therapy are compared with those of Case 7 without such therapy. It is quite clear that estradiol benzoate therapy resulted in a decrease in the urinary calcium excretion, but had little effect on the fecal calcium excretion during the 18 days of administration. However, the tendency for the fecal calcium to decrease in Case 9 after the therapy was stopped may well have been a delayed response to the therapy. The urinary citric acid values carried out and interpreted by Dr. Ephraim Shorr confirm his finding (17) of a rise during estrogen therapy.

\section{Osteoporosis of Cushing's syndrome}

Case 10. Cushing's Syndrome; Nephrolithiasis; Estradiol Benzoate and Testosterone Propionate Therapy.

The metabolic data of Case 10 are shown in graphic form in Figure 11. For data in tabular form for periods

Calcium Balances; on Serum Calcium, Phosphorus, and Alkaline Phosphatase Levels; on Urinary 17Ketosteroid Excretion and on Weight in a Male Patient with Osteoporotic Process Induced by OpERATION AND IMMOBILIZATION

For discussion, see text. 
EDWARD C. REIFENSTEIN, JR., AND FULLER ALBRIGHT

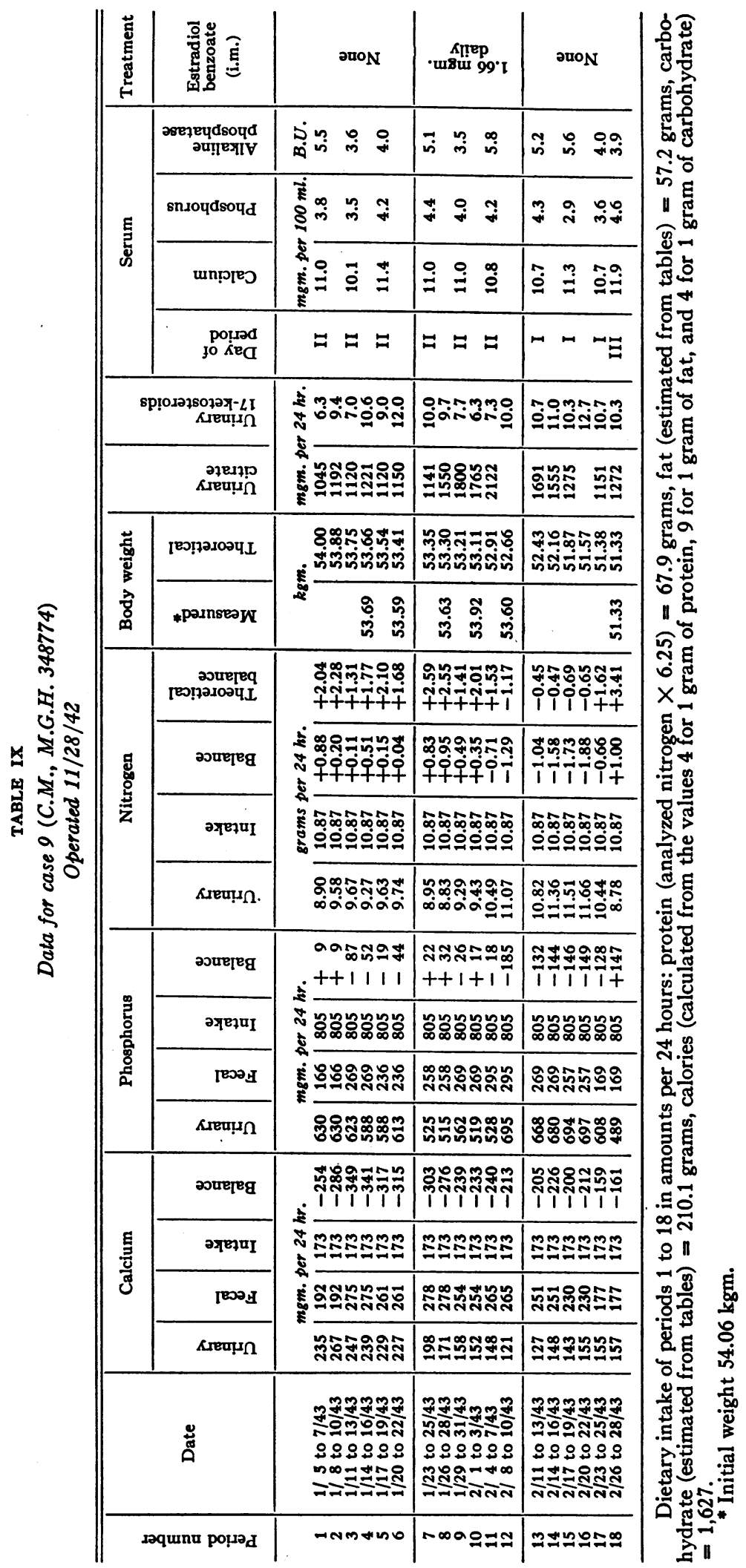




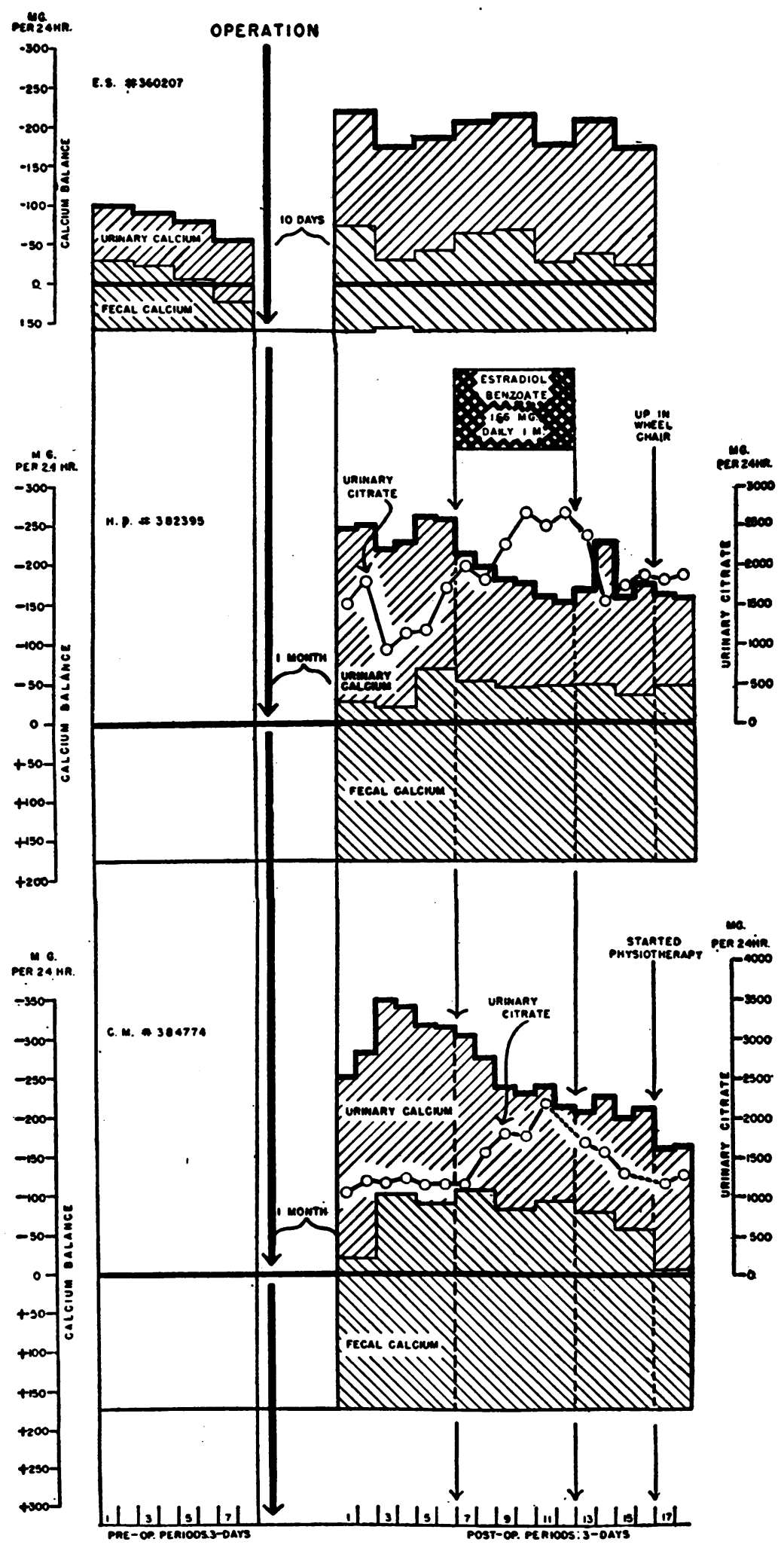

Fig. 10. Metabolic Data for Calcium of Cases 7, 8, and 9. Effect of Estradiol Benzoate as Compared with No Therapy on the Calctum Balances in Patients with Osteoporotic Process due to Operation AND IMMOBILIZATION

For discussion, see text. 


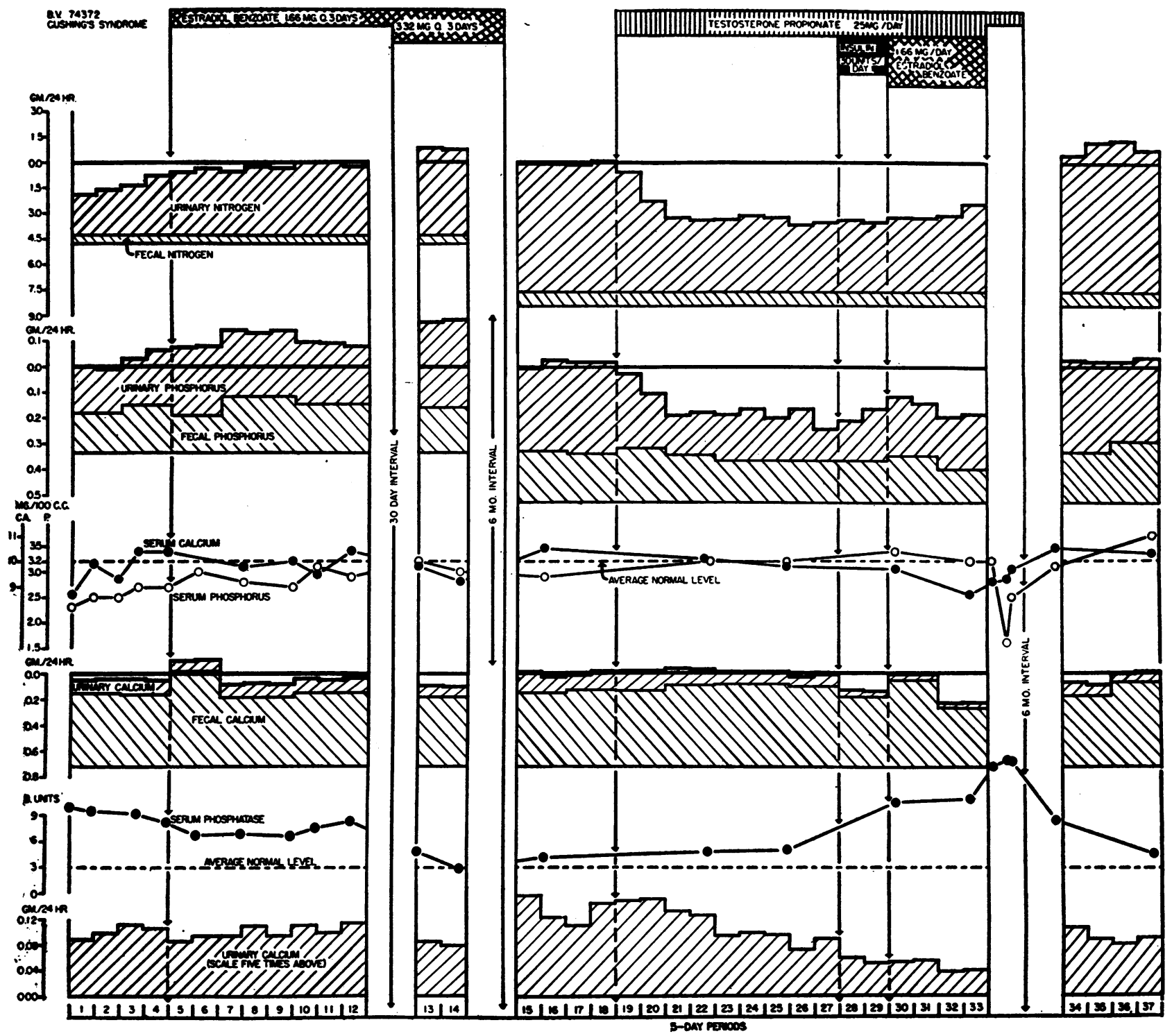

Fig. 11. Case 10 (B. V., M.G.H. 74372) : Effect of Estradiol Benzoate and Testosterone Propionate on Nitrogen, Phosphorus, and Calcium Balances, and on Serum Calcium, Phosphorus and Alkaline Phosphatase in a Female Patient with Osteoporosis due to Cushing's Syndrome

For discussion, see text.

At the bottom of the chart, the urinary calcium is shown separately on an enlarged scale.

1 through 33 , see (2). The study covers 37 five-day periods obtained on 4 hospital admissions. Two diets were used: one for periods 1 through 14, and a second for periods 15 through 37 . The nitrogen intake shown in Figure 11 for periods 17 through 33 is an analyzed value, and differs from that previously published which was taken from a table. The data in Figure 11 are self-explanatory. It should first be noted that the phosphorus balance corresponds reasonably well with the sum of the nitrogen and calcium balances during the last 23 periods, but not the first 14 . This suggests some constant error in the first 14 periods, probably the value for the nitrogen intake. A more detailed analysis to emphasize the close agreement between the nitrogen, potassium, phosphorus, and sulphur balances of periods 15 through 33 has already been published (9). Although Albright et al (2) concluded from these studies that estrogen was without beneficial effect, this was true with respect to the nitrogen balance but not altogether true with respect to the calcium balance. Thus, with the larger dose of estradiol benzoate in periods 13 to 14 there is an increase, probably significant, in the calcium balance. Further- 
more, when estradiol benzoate was added to testosterone propionate therapy in periods 30 through 33, there was a further fall in the urinary calcium excretion and an increase in the positive calcium balance. Other observations to be underlined in Figure 11 are: (1) the marked decrease in the urinary nitrogen, phosphorus, and calcium excretions with testosterone propionate therapy; (2) the marked rise in the serum phosphatase level when the increase in calcium balance became appreciable (see periods 30 through 33 ). Whereas Figure 11 suggested that insulin had a marked effect on calcium balance (see periods 28 and 29) the authors are inclined to discount this because of the essentially negative result in a second patient with Cushing's syndrome so treated (18).

Case 11. Cushing's Syndrome with Osteoporosis; Estradiol Benzoate, Testosterone Propionate, and Methyl Testosterone Therapy.

The metabolic data on Case 11 are shown in graphic form in Figure 12. For data in tabular form for periods 1 through 36 , see (2). The study covers 55 five-day periods obtained on 6 hospital admissions. The data in Figure 12 are self-explanatory. It should first be noted that the phosphorus balance corresponds reasonably well with the sum of the nitrogen and calcium balances throughout. As in Case 10, one cannot conclude, as did Albright, et al (2), that estrogen therapy is without beneficial effect. It was started before the metabolic study was initiated; so its initial effect is hard to evaluate (see periods 1 through 7); however, further studies undertaken 35 days after omitting estrogen show that the calcium balance has changed from positive to negative (compare periods 8 and 9 with 6 ). Other points to be noted in Figure 12 are: (1) the lowering of the urinary nitrogen, phosphorus, and calcium excretions with testosterone propionate therapy (periods 10 through 18, and 23 through 36) and with methyl testosterone therapy (periods 50 through 55); (2) the fact that the fecal phosphorus and calcium excretions were also lowered with these 2 testosterone compounds; (3) the quick rebound in the nitrogen and phosphorus and not the calcium metabolisms on cessation of testosterone propionate therapy (see periods 19 through 22); (4) the steady improvement in calcium metabolism with continued administration of testosterone propionate therapy; (5) the elevation of the serum phosphatase with improvement in the calcium balance; and (6) the rise in the serum phosphorus level following omission of estradiol benzoate therapy in period 6. The marked improvement in calcium balance in periods 29 through 36 is probably to be attributed to continued testosterone propionate therapy, but the initiation of vitamin $D$ therapy in period 29 makes the exact interpretation difficult. Dehydroisoandrosterone acetate in periods 42 to 46 did not prevent the rebound in nitrogen and phosphorus metabolisms from omission of testosterone propionate therapy.

Case 12. Cushing's Syndrome with Osteoporosis; Progesterone and Testosterone Propionate Therapy.

The metabolic data of Case 12 are shown in graphic form in Figure 13. For data in tabular form, see (2).
The study, conducted in 5-day periods, consisted of : (1) five control periods; (2) seven periods on progesterone therapy, $25 \mathrm{mgm}$. per day ; and (3) four periods on testosterone propionate therapy, $25 \mathrm{mgm}$. intramuscularly per day.

The data in Figure 13 are self-explanatory. As pointed out by Albright, et al (2), the progesterone therapy, if anything, had a slightly beneficial effect on nitrogen, phosphorus, and calcium. The effect was not nearly so marked as that obtained in periods 13 to 16 with testosterone propionate therapy. Of interest is the rise in the alkaline phosphatase level in period 16, when the calcium balance became appreciable. It should be noted that the 17-ketosteroid excretion was not lowered by progesterone or elevated by testosterone propionate; the latter finding is surprising, and not in agreement with other studies.

\section{CERTAIN THERAPEUTIC ASPECTS CONCERNING POST-}

\section{MENOPAUSAL OSTEOPOROSIS}

A large number of cases, many complicated by fractures, have been treated with estrogens alone and in combination with testosterone compounds during the past 5 years. As a group, these patients have responded very satisfactorily. Within weeks to months, the pain in the spine and other bones usually has been considerably or completely eliminated. There has frequently been an increase in weight, apparently an increase in the thickness of the skin and an improvement in the general well-being Whereas the study is impossible to control, we have the impression that fractures, especially of the hip, in old ladies have responded better than they would have otherwise. However, in spite of these favorable clinical manifestations, it has been difficult to produce undisputed evidence that the bones (excluding fracture-sites) as visualized by $x$-ray have become more calcified than before the therapy was instituted. Nevertheless, the recent films of several of the longest-treated cases are fairly convincing.

Dosages have ranged as follows: diethylstilbestrol 0.5 to $1 \mathrm{mgm}$. daily p.o., estrone sulfate ${ }^{6}$ 2.50 to $3.75 \mathrm{mgm}$. daily p.o., estradiol benzoate 1.66 to 3.32 mgm. 3 times a week i.m., and estradiol dipropionate $5 \mathrm{mgm}$. weekly i.m. A few patients have been treated by implantation of pellets. Excessive estrogenic effect on the endometrium has been controlled whenever a responsive uterus was present, by interrupting the estrogenic therapy periodically (every 4 to 6 weeks

\footnotetext{
6 Conjugated equine estrogens (Premarin [Ayerst, Mc-
} Kenna and Harrison]). 


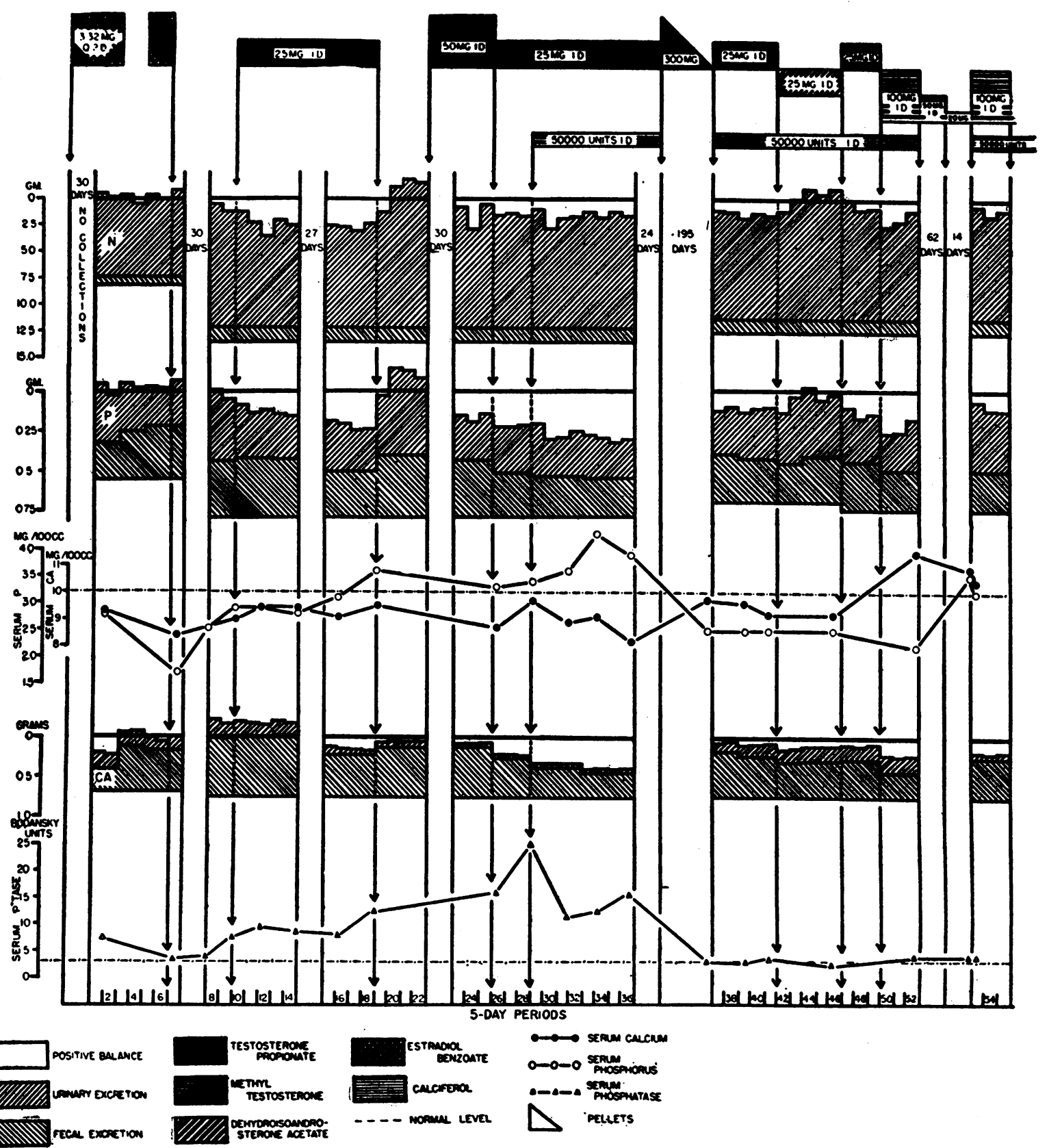

Fig. 12. Case 11 (R. B., M.G.H. 3397) : Effect of Estradiol Benzoate, Testosterone Propionate and Methyl Testosterone on Nitrogen, Phosphorus, and Calcium Balances; and on Serum Calcium, Phosphorus, and Alkaline Phosphatase in a Female Patient with Osteoporosis due to Cushing's SYNDROME

For discussion; see text.

for 1 to 2 weeks), or by administering at regular intervals (every 4 to 6 weeks) a course of progesterone ( $5 \mathrm{mgm}$. daily i.m. for 5 days) or of anhydro-hydroxyprogesterone ( 40 to $60 \mathrm{mgm}$. daily p.o. for 5 days). Testosterone compounds can- not be given in most patients with the impunity suggested from Case 4; she was remarkably free from the masculinizing effect of such medication. Most women will not tolerate more than $300 \mathrm{mgm}$. per month of androgen. We have given methyl 


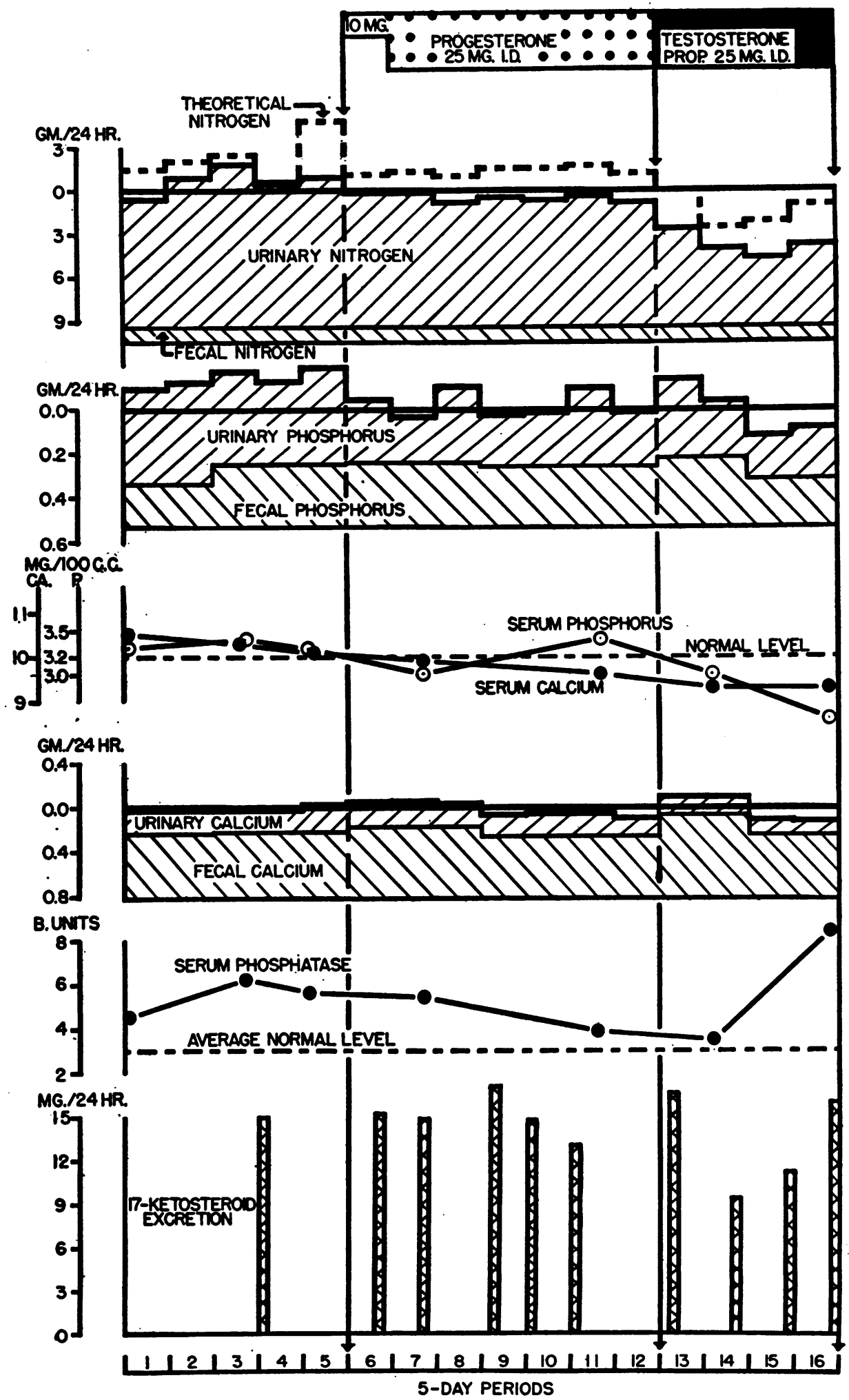

Fig. 13. CAse 12 (B. A., M.G.H. 234190) : Effect of Progesterone and Testosterone Propionate on Nitrogen, Phosphorus, and Calcium Balances; on Serum Calcium, Phosphorus, and Alkaline Phosphatase; and on Urinary 17-Ketosteroid Excretion in a Female Patient with Osteoporosis due to Cushing's Syndrome

For discussion, see text. 
testosterone 10 to $20 \mathrm{mgm}$. daily p.o., and testosterone propionate 10 to 20 or $25 \mathrm{mgm}$. a week i.m. One of the most successful methods of administering testosterone compounds to these patients is to implant one or two pellets of testosterone (75 mgm. each [Schering]) every 3 to 4 months. We usually give some form of testosterone at least for the first 6 to 12 weeks.

Since many of the steroids cause sodium retention, the above endocrine therapy may cause edema in certain elderly patients, especially if they have low serum protein levels. If this is not controlled by a low sodium chloride diet, and/ or ammonium chloride, the steroid therapy'may have to be modified.

Because of the possible danger that continued estrogenic medication may lead to cancer, it has been our practice to interrupt the medication for 7 to 14 days every 4 to 6 weeks, even though the uterus is out. An examination of the vaginal smear every 6 months provides a further safeguard (19). If the uterus is in, a record should be kept of the vaginal bleeding; any bleeding not according to plan (that is, not following estrogen or progesterone withdrawal) should promptly be investigated further.

Since osteoporosis is a deficiency in bone matrix protoplasm, a high protein diet is probably indicated; since it is not a disease of calcium and phosphorus metabolism, excessively high intakes of these minerals and of vitamin $\mathrm{D}$ are probably not indicated. Prolonged immobilization should, of course, be avoided if possible, because of the danger of superimposed atrophy of disuse.

\section{SUMMARY}

1. Osteoporosis is defined as that form of undermineralization of bone in which the primary defect is a hypofunction of the osteoblasts in laying down bone matrix; eight etiological subgroups are listed.

2. The effect of certain steroid hormones (notably estrogens, androgens, and progesterone) has been studied in 11 cases of osteoporosis: 5 cases of the post-menopausal type, 1 case of the senile type, 2 cases of the type seen following orthopedic operations (atrophy of disuse), and 3 cases of the Cushing's syndrome type.

3. Estrogens in the 2 forms used (estradiol ben- zoate and diethylstilbestrol) decreased the calcium and phosphorus excretions in the 4 types of osteoporosis studied. Additional observations on estrogen therapy follow.

a. The fecal as well as the urinary calcium and phosphorus excretions were decreased in most instances.

b. The effects were usually manifested within 6 days ; did not reach a maximum until after 30 days; and persisted for 30 to 50 days after cessation of therapy.

c. The synthetic estrogen, diethylstilbestrol, appeared to be as effective as the naturallyoccurring estrogen, estradiol.

d. The ranges of dosages employed were for estradiol benzoate $3.32 \mathrm{mgm}$. daily to 1.66 $\mathrm{mgm}$. every 3 days intramuscularly, and for diethylstilbestrol 1 to $15 \mathrm{mgm}$. daily by mouth. There was no convincing evidence that the larger doses of estradiol benzoate were more effective than the smaller; in one instance (Figure 3) $3.32 \mathrm{mgm}$. seemed less effective than $1.66 \mathrm{mgm}$. every third day. In the one case studied, $15 \mathrm{mgm}$. of diethylstilbestrol daily was probably more effective than $1 \mathrm{mgm}$. daily.

e. The serum phosphorus levels, which tend to be high in the post-menopausal group, fell in almost all instances.

f. The serum alkaline phosphatase levels, contrary to expectations, did not rise.

g. The urinary nitrogen excretion showed a poorly-sustained decrease.

h. The urinary 17-ketosteroid excretion showed a moderate decrease with estradiol.

4. Androgens in the 2 forms used (testosterone propionate and methyl testosterone) likewise decreased the calcium and phosphorus excretions in the 3 types of osteoporosis (post-menopausal, senile, and Cushing's syndrome) studied. Additional observations on androgen therapy follow.

a. As in the case of estrogens, the fecal as well as the urinary calcium and phosphorus excretions were decreased; the effect of the therapy on the calcium metabolism was slow in reaching its maximum, and persisted for a long time after cessation of therapy; the serum phosphorus levels tended to fall; the 
serum alkaline phosphatase levels failed to rise except in the three cases of Cushing's syndrome.

b. In contrast to estrogens, the decrease in the urinary nitrogen excretion was marked and prolonged.

c. The ranges of dosages employed were for testosterone propionate 25 to $50 \mathrm{mgm}$. daily intramuscularly, and for methyl testosterone 40 to $100 \mathrm{mgm}$. daily by mouth.

d. Methyl testosterone appeared to be as effective as testosterone propionate.

5. Progesterone, in the dosages of 10,25 , and $100 \mathrm{mgm}$. daily, had no definite effect whether given alone or in combination with estrogen.

6. The effect on the calcum metabolism of estrogen and androgen in combination was greater than that of either alone in the post-menopausal and senile groups.

7. In Cushing's syndrome estrogen probably does have a beneficial effect on the calcium balance, previous statements to the contrary from this clinic notwithstanding! However, testosterone compounds have a much more striking effect in this condition, as opposed to other types of osteoporosis.

8. The data contain observations on the effect of pregnenolone and dehydroisoandrosterone acetate.

9. A short discussion of certain therapeutic aspects of post-menopausal osteoporosis is included.

The authors are grateful to Drs. Max Gilbert and Erwin Schwenk of the Schering Corporation, Bloomfield, New Jersey, for generous supplies of estradiol benzoate (Progynon-B), estradiol dipropionate (Progynon-DP), testosterone propionate (Oreton), methyl testosterone (Oreton-M), progesterone (Proluton), anhydro-hydroxyprogesterone (Pranone), dehydroisoandrosterone acetate, pregnenolone, and other steroids.

The authors are indebted to Drs. Charles H. Burnett, Russell. W. Fraser, Anne Pappinheimer Forbes, Laurence W. Kinsell, Harry F. Klinefelter, Jr., William Parson, Patricia H. Smith, and Hirsh W. Sulkowitch for professional assistance; and to Esther Bloomberg, Dorothy F. Bryant, Evelyn Caroll, Lowell D. Cox, Eleanor F. Dempsey, Elizabeth C. Donaldson, Grace C. Griswold, Marion MacAulay, Robin M. Suby, Shirley L. Wells, and Priscilla White for technical assistance.

\section{APPENDIX \\ Case histories}

Case 1. F. F. (M.G.H. 156453), a 42-year-old woman, had a bilateral oophorectomy at the age of 41 for endometriosis; following the operation she had "nocturnal seizures," the exact nature of which was not determined. During the following year there was a gradual onset of back pain with increasing dorsal kyphosis and a loss of energy. On admission one year after operation, the patient was in good physical condition except for the deformities of her spine; her blood pressure was 130/80. $\mathrm{X}$-rays revealed typical codfish deformity of many of the dorsal and lumbar vertebrae, a collapse of some vertebrae, and anterior wedging of others. Laboratory studies: serum calcium $10.5 \mathrm{mgm}$. per cent, serum phosphorus $4.2 \mathrm{mgm}$. per cent, serum alkaline phosphatase 3.6 Bodansky units, serum total protein 7.3 grams per cent, normal glucose tolerance test, some hypoglycemia unresponsiveness in an insulin tolerance test, basal metabolic rate of minus 6 , follicle-stimulating hormone test positive for 25 mouse units per $100 \mathrm{ml}$., and 17-ketosteroid excretion of $4.3 \mathrm{mgm}$. per 24 hours. This case was mentioned in previous communications (1 [Case 1], 3 [Case 37], 20 [Case 82], 21).

Case 2. E. P. (M.G.H. 203540), a 60-year-old patient, had a physiological menopause at 53. Thirteen months before admission she fell down 6 steps and fractured her first lumbar vertebra; she was kept in bed 5 months for this injury, and then allowed up with a brace. Eight months before admission the 9th dorsal vertebra collapsed. Except for back and chest pain, the patient had no complaints, and was in good general health upon admission. Her blood pressure was 120/90. X-ray examination revealed the fractures of the first lumbar and the 9th dorsal vertebrae, marked osteoporosis of the spine and pelvis, but not of the skull, and gall stones. Laboratory studies: serum calcium $10.1 \mathrm{mgm}$. per cent; serum phosphorus $3.5 \mathrm{mgm}$. per cent; serum alkaline phosphatase 3.7 Bodansky units; serum total protein 7.6 grams per cent; no Bence-Jones protein in the urine. This case was mentioned in previous communications (1 [Case 2], 3 [Case 13], 20 [Case 85], 21).

Case 3. A. M. R. (M.G.H. 29358), a 60-year-old physician, developed menopause at 45 following radium treatment of submucous fibroids. Four years before admission she experienced pain in the back while trying to raise a window, and in the ensuing 4 years developed several fractures of vertebrae and progressive deformity of the spine. Physical examination on admission revealed the deformity of the spine and otherwise no abnormalities. Her blood pressure was 148/90. X-ray examination showed deformities of several thoracic and the first lumbar vertebrae, and osteoporosis of the bones of the spine and pelvis but not of the skull. Laboratory studies: serum calcium $10.1 \mathrm{mgm}$. per cent; serum phosphorus $3.0 \mathrm{mgm}$. per cent; serum phosphatase 3.7 Bodansky units; serum total protein 6.3 grams per cent. This case has been mentioned in previous communications (1 [Case 3], 3 [Case 32], 20 [Case 84], 21). 
Case 4. R. W. (M.G.H. 319940), a 56-year-old woman, had a cholecystectomy at 26 , and thyroidectomy for thyrotoxicosis at 46 . At 48 , an artificial menopause was induced with radium for metropathia hemorrhagica. Three years before admission the patient strained her back opening a heavy window, and thereafter had several episodes of sharp pain in the back when lifting. Physical examination showed a nervous woman with a tremor of her head, and considerable deformity of her back. Her blood pressure was $115 / 75$. X-ray examination revealed extensive osteoporosis with multiple fractured vertebrae; bones of skull were approximately normal in density. Laboratory studies: no abnormalities of the urine, stools, or blood cells; urine calcium 2 to 4 plus by the Sulkowitch test; serum calcium 10.6 mgm. per cent; serum phosphorus 3.1 mgm. per cent; serum alkaline phosphatase 3.7 Bodansky units; serum chloride 93.2 m.eq. per 1.; serum carbon dioxide combining power 28.1 m.eq. per 1.; non-protein nitrogen level $26 \mathrm{mgm}$. per cent; and total protein 7.8 grams per cent with an albumin/globulin ratio of 1.7 . Electrocardiographic tracing was normal; follicle-stimulating hormone excretion in the urine was high (consistent with the menopause). This case has been mentioned in a previous communication (21).

Case 5. S. B. (M.G.H. 430664), a 58-year-old woman, had at the age of 28 a bilateral oophorectomy with a hysterectomy for pelvic lacerations following childbirth. For some years she had occasional hot flashes and attacks of palpitation and nervousness. At the age of 50 she began to notice weakness and the gradual onset of skeletal deformities involving the skull, shoulder girdle, lower ribs, pelvis, and bones of the legs. At 54 she had acute tonsillitis, and then a tonsillectomy. At 57 she had pneumonia, and after 3 weeks in bed, increased weakness and pain in her tibiae. About this time she used braces on her legs because of difficulty in walking. Shortly afterward she developed low-back pain on weight-bearing.

On admission, the patient was undernourished and deformed with atrophic skin and muscles, dorsal kyphosis and right cervical-dorsal scoliosis, enlarged parietal bosses, bowing of the femora and tibiae, and collapse of the lumbar spine so that the ribs touched the wings of the iliae. The chest was distorted; veins of the neck were distended; cor pulmonale was present; blood pressure was $156 / 80$.

$\mathrm{X}$-rays of the skull, shoulder girdle, lower ribs, pelvis, femora, tibiae, and entire thoracic and lumbar spine except for the upper three dorsal vertebrae showed Paget's disease; in addition there were marked generalized decreased density of bones and typical codfish deformity of many vertebrae. There were pulmonary fibrosis, cardiac enlargement and displacement, and tortuosity of the aorta. Laboratory studies : serum calcium $10.5 \mathrm{mgm}$. per cent, serum phosphorus $4.2 \mathrm{mgm}$. per cent, serum alkaline phosphatase 34.3 Bodansky units, serum total protein 7.3 grams per cent, serum non-protein nitrogen $31 \mathrm{mgm}$. per cent, serum sodium 140.0 m.eq. per 1., serum potassium 4.7 m.eq. per 1., serum chloride 101 m.eq. per 1. , serum carbon dioxide content 34.2 m.eq. per 1., follicle-stimulating hormone test positive for 192 mouse units per 24 hours, and 17-ketosteroid excretion of $2.6 \mathrm{mgm}$. per 24 hours. The venous pressure was $65 \mathrm{~mm}$. of water; the vital capacity was $1,200 \mathrm{ml}$.

Case 6. M. H. (M.G.H. 278511), a male of 72 years, developed pain in the back after a minor. injury 1 year before admission (1-1-41). The symptoms persisted in spite of local therapy, and he was referred to the hospital. The only abnormal findings on physical examination were a thin skin and deformities of the spine; his blood pressure was $140 / 80$. X-ray examination of the spine showed marked decrease in density of the vertebrae with a codfish deformity of some, and wedging or collapse of others. Laboratory studies: serum calcium $10.0 \mathrm{mgm}$. per cent; serum phosphorus $3.1 \mathrm{mgm}$. per cent; serum alkaline phosphatase 4.2 Bodansky units; serum total protein 7.0 grams per cent; non-protein nitrogen $18 \mathrm{mgm}$. per cent; urinary 17 -ketosteroid excretion 7.2 and $6.9 \mathrm{mgm}$. per 24 hours; follicle-stimulating hormone excretion in the urine normal; gastric acidity normal. The normal level of the follicle-stimulating hormone excretion is evidence against the idea of the osteoporosis having been due to the "male menopause." This case has been mentioned in previous communications $(6,9,21)$.

Case 7. E. S. (M.G.H. 360207), a female of 35 years, had poliomyelitis at the age of 9 involving the left leg alone, and since the age of 14 had worn a 6-pound brace on the left leg. She had always been very active. For the 10 years prior to study she had had metatarsal pain in the right foot, and for 3 years had turned her right ankle frequently. She was admitted for a triple arthrodesis and muscle transplant to strengthen the right ankle. The menstrual history was normal. From the point of view of the experiment the patient can be considered a normal adult female in every respect, except for the residuals of the poliomyelitis of the left leg; her blood pressure was $120 / 80$. Laboratory studies: serum calcium 9.8 mgm. per cent; serum phosphorus $3.5 \mathrm{mgm}$. per cent; serum alkaline phosphatase 2.4 Bodansky units; and serum total protein 4.7 grams per cent; urinary $17-$ ketosteroid excretion $7.6 \mathrm{mgm}$. per 24 hours. This case has been mentioned briefly elsewhere (22).

Case 8. H. D. (M.G.H. 382395), a male fireman of 50 years, fell 3 stories and suffered fractures of ribs, pelvis, right tibia and right fibula, and multiple contusions and abrasions. The patient was in shock on admission, but responded promptly to a blood transfusion. On physical examination he was found to be a well-preserved man without organic disease; blood pressure was 110/60. A Kirschner wire was inserted through the os calcis and a Zimmer bow applied. During the next 2 weeks the fractures were reduced by traction and by several manipulations under anesthesia. The patient was transferred to the metabolic ward where studies were begun 44 days after the accident. Laboratory studies: serum calcium $10.7 \mathrm{mgm}$. per cent; serum phosphorus $3.3 \mathrm{mgm}$. per cent; serum alkaline phosphatase 2.7 Bodansky units; serum total protein 6.7 grams per cent. This case has been mentioned briefly elsewhere (23).

Case 9. C. M. (M.G.H. 348774), a male of 24 years, sustained a fracture of the pelvis and of the right femur in an automobile accident 9 months before study. The fe- 
mur failed to unite properly and, although the patient was active and able to walk about with a cane, he had unusual motion and instability in his right femur because of the poor union. He was readmitted for bone grafting. Physical examination revealed a young adult male who was normal in all respects except for the incomplete union of his right femur; his blood pressure was 105/60. Laboratory studies: serum calcium $10.3 \mathrm{mgm}$. per cent; serum phosphorus $4.5 \mathrm{mgm}$. per cent; serum alkaline phosphatase 2.9 Bodansky units, and serum total protein 6.0 grams per cent. This case has been mentioned briefly elsewhere (24).

Case 10. B. V. (M.G.H. 74372), a female of 25 years, with Cushing's syndrome of $\mathbf{5}$ years duration. The case history of this patient has been published elsewhere (2 [Case 1]). This case has been mentioned also in other previous communications (6, 9, 20 [Case 37]).

Case 11. R. B. (M.G.H. 3397), a female of 50 years, with Cushing's syndrome of 5 years duration. The case history of this patient has been published elsewhere (2 [Case 2]). This case has been mentioned also in other previous communications $(6,9,20$ [Case 36], 25 [Case 2]).

Case 12. B .A. (M.G.H. 234190), a female of 43 years, with Cushing's syndrome of 6 years duration. A complete case history with autopsy findings is reported elsewhere (26). This case has also been mentioned in previous communications (2 [Case 3], 20 [Case 38]).

\section{BIBLIOGRAPHY}

1. Albright, F., Bloomberg, E., and Smith, P. H., Postmenopausal osteoporosis. Tr. Assoc. Am. Physicians, 1940, 55, 298.

2. Albright, F., Parson, W., and Bloomberg, E., Cushing's syndrome interpreted as hyperadrenocorticism leading to hypergluconeogenesis; results of treatment with testosterone propionate. J. Clin. Endocrinol., 1941, 1, 375.

3. Albright, F., Smith, P. H., and Richardson, A. M., Post-menopausal osteoporosis: its clinical features. J. A. M. A., 1941, 116, 2465.

4. Reifenstein, E. C., Jr., and Albright, F., Paget's disease: its pathologic physiology and the importance of this in the complications arising from fracture and immobilization. New Eng. J. Med., 1944, 231, 343.

5. Albright, F., Burnett, C. H., Cope, O., and Parson, W., Acute atrophy of bone (osteoporosis) simulating hyperparathyroidism. J. Clin. Endocrinol., 1941, 1, 711.

6. Albright, F., Cushing's syndrome. Its pathological physiology, its relationship to the adrenogenital syndrome, and its connection with the problem of the reaction of the body to injurious agents ("alarm reaction" of Selye). The Harvey Lecture Series, 1942-1943, 38, 123.

7. Selye, H., The alarm reaction. Cyclopedia Med. Surg. and Spec., F. A. Davis Company, Phila- delphia, 1940, 15. Also, Selye, H., The general adaptation syndrome and the diseases of adaptation. J. Clin. Endocrinol., 1946, 6, 117.

8. Reifenstein, E. C., Jr., Kinsell, L. W., and Albright, F., Observations on the use of the serum phosphorus level as an index of pituitary growth hormone activity; the effect of estrogen therapy in acromegaly. Endocrinol., 1946, 39, 71. Also Conference on Metabolic Aspects of Convalescence Including Bone and Wound Healing. Trans. of 12th Meeting, February 4-5, 1946, p. 97; distributed by Josiah Macy, Jr. Foundation, New York.

9. Reifenstein, E. C., Jr., Albright, F., and Wells, S. L., The accumulation, interpretation, and presentation of data pertaining to metabolic balances, notably those of calcium, phosphorus, and nitrogen. J. Clin. Endocrinol., 1945, 5, 367.

10. Talbot, N. B., Saltzman, A. H., Wixom, R. L., and Wolfe, J. K., The colorimetric assay of urinary corticosteroid-like substances. J. Biol. Chem., 1945, $160,535$.

11. Klinefelter, H. F., Jr., Albright, F., and Griswold, G. C., Experience with a quantitative test for normal or decreased amounts of follicle stimulating hormone in the urine in endocrinological diagnosis. J. Clin. Endocrinol., 1943, 3, 529.

12. Abels, J. C., and Dobriner, K., Conference on Metabolic Aspects of Convalescence Including Bone and Wound Healing, Transactions of Seventh Meeting, June $9-10,1944$, p. 122 ; distributed by Josiah Macy, Jr. Foundation, New York.

13. Farquharson, R. F., Salter, W. T., Tibbets, D. M., and Aub, J. C., Studies of calcium and phosphorus metabolism. XII. The effect of the ingestion of acid-producing substances. J. Clin. Invest., 1931, 10, 221.

14. Howard, J. E., Parson, W., and Bigham, R. S., Jr., Studies on fracture convalescence. III. The urinary excretion of calcium and phosphorus. Bull. Johns Hopkins Hosp., 1945, 77, 291.

15. Forbes, A. P., Donaldson, E. C., Reifenstein, E. C., Jr., and Albright, F., The effect of trauma and disease on the urinary 17 -ketosteroid excretion in man. J. Clin. Endocrinol. To be published.

16. Browne, J. S. L., Conference on Metabolic Aspects of Convalescence Including Bone and Wound Healing, Transactions of the Fifth Meeting, October 8-9, 1943, p. 91; distributed by Josiah Macy, Jr. Foundation, New York.

17. Shorr, E., Bernheim, A. R., and Taussky, H., The relation of urinary citric acid excretion to the menstrual cycle and the steroidal reproductive hormones. Science, 1942, 95, 606.

18. Reifenstein, E. C., Jr., and Albright, F., Conferences on Metabolic Aspects of Convalescence Including Bone and Wound Healing, Transactions of the Fifth Meeting, October 8-9, 1943, p. 79; distributed by Josiah Macy, Jr. Foundation, New York.

19. Fremont-Smith, M., Graham, R. M., Janzen, L. T., and Meigs, J. V., The vaginal smear in the diag- 
nosis of uterine cancer. J. Clin. Endocrinol., $1945,5,40$.

20. Fraser, R. W., Forbes, A. P., Albright, F., Sulkowitch, H., and Reifenstein, E. C., Jr., Colorimetric assay of 17-ketosteroids in urine; a survey of the use of this test in endocrine investigation, diagnosis, and therapy. J. Clin. Endocrinol., 1941, 1, 234.

21. Reifenstein, E. C., Jr., Albright, F., Parson, W., and Bloomberg, E., The effect of estradiol benzoate, of testosterone propionate, and of combinations of both on post-menopausal osteoporosis and senile osteoporosis. Endocrinol., 1942, 30, S1024.

22. Reifenstein, E. C., Jr., and Albright, F., Conferences on Metabolic Aspects of Convalescence Including Bone and Wound Healing, Transactions of First Meeting, September 11-12, 1942, p. 37; Transactions of Second Meeting, December 11-12, 1942, p. 69 and 96; and Transactions of Fourth Meeting, June 11-12, 1943, p. 77; distributed by Josiah Macy, Jr. Foundation, New York.
23. Reifenstein, E. C., Jr., and Albright, F., Conferences on Metabolic Aspects of Convalescence Including Bone and Wound Healing, Transactions of Third Meeting, March 12-13, 1943, p. 63; and Transactions of Fourth Meeting, June 11-12, 1943, p. 77; distributed by Josiah Macy, Jr. Foundation, New York.

24. Reifenstein, E. C., Jr., and Albright, F., Conferences on Metabolic Aspects of Convalescence Including Bone and Wound Healing, Transactions of Fourth Meeting, June 11-12, 1943, p. 77; distributed by Josiah Macy, Jr. Foundation, New York.

25. Reifenstein, E. C., Jr., Forbes, A. P., Albright, F., Donaldson, E., and Carroll, E., Effect of methyl testosterone on urinary 17-ketosteroids of adrenal origin. J. Clin. Invest., 1945, 24, 416.

26. Albright, F., and MacMahon, H. E., Clinical Pathological Conference. Bull. New Eng. Med. Center, 1941, 3, 35. 